\title{
PRODUÇÕES DE SIGNIFICADOS MATEMÁTICOS EM OBRAS DE LEONARDO DA VINCI
}

\section{PRODUCTIONS OF MATHEMATICAL MEANINGS OUT OF LEONARDO DA VINCI ARTPIECES}

\author{
Rodolfo Chaves, Caio Lopes Rodrigues* \\ Instituto Federal do Espírito Santo - Campus Vitória (*) \\ Coordenação de Matemática \\ Grupo de Pesquisa em Matemática Pura, Aplicada e Educação Matemática \\ E-mail: rodolfochaves20@gmail.com , caiolr1988@hotmail.com
}

\begin{abstract}
Resumo
Tomamos alguns padrões numéricos e geométricos como pré-requisitos a possíveis leituras de algumas obras de Arte. Predispomo-nos a analisar, como forma de leitura, a existência de possíveis padrões matemáticos em três obras de Leonardo Da Vinci. Ao estabelecermos análises a partir de leituras históricas objetivamos levar o leitor a refletir em possibilidades e perspectivas de se tomar a relação dual Matemática e Arte como possível forma de procedimento de ensino a partir de um ambiente investigativo de aprendizagem. $O$ objetivo não se restringe à busca da transversalidade entre Matemática e Arte, mas apresentar a Matemática como ferramenta de leitura de processos, fenômenos, modelos e textos, dos quais se destacam obras de Arte. Este texto fundamenta-se a partir da pesquisa de natureza qualitativa, bibliográfica e exploratória, porém, também do tipo participante, visto que todos os procedimentos foram discutidos em sessões plenárias do Grupo de Pesquisa em Matemática Pura, Aplicada e Educação Matemática - Gepemem.
\end{abstract}

Palavras-chave: história da matemática. os elementos. padrões numéricos. padrões geométricos.

\begin{abstract}
For this work, we reached for numerical and geometric patterns as prerequisites to possible art piece readings. We predisposed ourselves to analyze, as a way of reading, the existence of possible mathematical patterns in three works by Leonardo Da Vinci. While formulating analyzes from historical readings aim to get the reader to reflect on the possibilities and prospects of taking the dual relationship Mathematics and Art as a possible educational procedure to create an investigative learning environment. The goal is not restricted to the pursuit of crossing Mathematics and Arts, but to present Mathematics as a tool for reading processes, phenomena, models and texts, among which are artworks. This text is based on research of qualitative, bibliographic and exploratory nature, but is also the participant research, since all procedures were discussed in plenary sessions of the Pure Mathematics, Applied Mathematics and Education Research Group - Gepemem.
\end{abstract}

Keywords: history of mathematics. the elements. numerical patterns. geometric patterns. 


\section{PROBLEMÁTICA}

\subsection{A relação primitiva de Matemática e Artes e a gênese da ruptura entre as mesmas}

A Matemática como área do conhecimento na História da humanidade é também tomada como ferramenta de leitura do mundo em diversas áreas - Física, Química, Biologia, História, Filosofia, Geografia, Música, Artes, Astronomia, Linguagens etc.

Ao retratar paisagens e animais e, mais tarde, esculpir em ossos marcas que representavam os animais capturados, o homem primitivo iniciou a busca da organização do seu entorno por meio da Arte e da Matemática (ZALESKI FILHO, 2013, p. 13).

O uso de seus princípios, conceitos e métodos, ao longo dos tempos, tem sido relevante à construção e à transformação de sociedades. Desde a pré-história, como descrito na citação antecedente, há relatos de sua utilização. Foi estudada e empregada por babilônios, chineses e gregos, por exemplo. Foi base de pensamentos de grandes nomes na História das civilizações. Platão colocou na inscrição da porta de entrada de sua academia: "Que ninguém ignorante em Geometria entre aqui.". Aristóteles e Pitágoras ${ }^{1}$, dentre outros pensadores gregos da época, direta ou indiretamente, apoiaram o estudo da Matemática, tanto na sua forma abstrata - e até esotérica - quanto no auxílio de resolução de problemas práticos. O que leva a inferir que a Matemática foi de suma importância na base da formação das sociedades antigas e a relação entre Matemática e Arte não é fruto de modismo contemporâneo ou pós-moderno.

Com a construção de armas e utensílios utilizando pedras, ossos e madeira, que depois de prontos eram decorados, começou a existir também a convivência entre formas, tamanhos ou dimensões com símbolos e padrões. No decorrer da história humana, a Arte e a Matemática continuaram a contribuir para organizar e explicar as aquisições culturais (ZALESKI FILHO, 2013, p. 14).

Seu estudo não era tão-somente destinado a resolver problemas, pois para ele a Matemática foi tomada como Arte e Filosofia, técnica e ciência. Quase uma religião. Desde a antiguidade clássica,

\footnotetext{
${ }^{1}$ (580 a 500 a.C.) filósofo e matemático grego nascido em Samos. Teve como mestres e interlocutores Tales de Mileto - precursor do raciocínio dedutivo e da Geometria Demonstrativa e um dos sete sábios da Antiguidade - Anaximandro Sonchi - sacerdote egípcio - e Zaratustra, dentre outros.
} 
na Arte grega, já era possível observar certa preocupação com a busca exacerbada pela simetria, pela beleza clássica a partir da estética que tomava a relação áurea como padrão. Na Arte romana, por exemplo, mosaicos eram construídos a partir de soluções daquilo que hoje designamos por matrizes - para arcos, para distribuição de cores, para ocupação espacial. A precisão e marcação juntavam-se a todos os anseios e desejos do artista de chegar ao ápice de sua obra prima, sendo a Matemática o alicerce para o aperfeiçoamento das obras artísticas.

Contudo, os pitagóricos, a partir da instituição do regime de verdade de que "Tudo é número", abrem espaço à perpetuação da crença de que a Matemática, por si só, poderia explicar o mundo não necessitando, para tal, de nenhuma outra vertente do conhecimento, incluindo aí também a Arte. Tal pensamento "em conjunto com o desprezo que Platão sentia pelos artistas plásticos coloca a Matemática e a Arte em patamares distintos e pode ter contribuído para o afastamento entre a Arte e a Matemática" (ZALESKI FILHO, 2013, p. 25).

[...] em algum momento da história da humanidade, a Arte "afastou-se" da Matemática e de outros campos das ciências. Qual o motivo, ou quais são os motivos desse afastamento? Talvez uma das razões tenha sido uma herança da Filosofia Grega: a ideia de um mundo dividido em superior e inferior [...] (ZALESKI FILHO, 2013, p. 13)

\subsection{Uma possível gênese à descontextualização do ensino da Matemática}

Chaves (2004, p. 160-161) destaca que um ambiente de aprendizagem pautado em um currículo rígido, onde o aluno é colocado como um ser passivo às informações advindas do professor por meio de exposições homiléticas, não é exclusividade das sociedades modernas e pós-modernas. Arquitas, responsável pela continuidade da tradição pitagórica, pôs a Aritmética acima da Geometria, contudo, sua relação com os números não era tão esotérica como para Pitágoras ou mística e religiosa como para Filolau de Crotona.

Arquitas parece ter dado considerável atenção ao papel da matemática no aprendizado, e foi-lhe atribuída a designação dos quatro ramos no quadrivium matemático - aritmética (ou números em repouso), geometria (ou grandezas em repouso), música (ou números em movimento) e astronomia (ou grandeza em movimento). Esses temas, juntos com o trivium consistindo de gramática, retórica 
e dialética (ou Aristóteles atribuía a Zeno), constituíram mais tarde as sete artes liberais, portanto o papel proeminente que a matemática desempenhou na educação se deve em não pequena medida a Arquitas. (BOYER, 1978, p. 52)

Para negar o paradigma existente - que consagra a hegemonia do Ensino Tradicional de Matemática (ETM), pautado em verdades cristalizadas, que põem a ordem curricular acima do diálogo, da criatividade e da investigação como forma de aprendizagem - Chaves (2004) aponta que, após Arquitas, que valorizava a música, o que vemos é um apego ao que é estático onde a ideia de movimento foi gradativamente esquecida, tornando-se assim descontextualizada.

Plotino, que espiritualizava a Arte, transcende Platão e defende que

a imitação dos objetos visíveis é um motivo para a atividade artística cuja finalidade é intuir as essências ou ideias. Para ele, a Arte, além de uma atividade produtiva, é um meio de conhecimento da Verdade. (ZALESKI FILHO, 2013, p. 25) 


\section{JUSTIFICATIVA}

\subsection{Um possivel entendimento a respeito de nossas reflexões}

Ao longo deste texto abordaremos alguns padrões (como pré-requisitos às leituras que realizamos em algumas obras); sobretudo, numéricos e geométricos, pois entendemos que é peculiar ao ser humano, bem como a outros animais - os corvos ${ }^{2}$, por exemplo -, avaliar, analisar e comparar padrões, mas um padrão não é um olhar universal. Há padrões e depositar um olhar a respeito de uma obra de Arte, de um foco em relação à natureza ou na leitura de um texto, é peculiar a cada indivíduo que tomará como referência sua trajetória, seu entendimento de mundo, suas concepções e regime de verdades com qual está comprometido ou tomado. Daí a relevância de realizarmos uma - mesmo que breve - arqueologia a respeito de padrões tomados pela História da humanidade.

Ao longo da história, número e números têm tido uma grande influência na nossa cultura e na nossa linguagem. Há muitas palavras associadas aos números, por exemplo, bicicleta tem duas roas, um tripé tem três pés, um octogenário já viveu 8 décadas, etc. A história dos números começa antes da nossa própria história. Certas aves são capazes de se aperceber se foi retirado algum ovo do seu ninho. Provavelmente terão uma ideia primária sobre o número de ovos que lá deveria estar. Dantzig descreve uma experiência em que os corvos reconhecem até quatro homens (SILVA; PENA, 2014, p.4) (ipsis verbis)

\subsection{O porquê Leonardo Da Vinci}

Nossa vontade de construir conhecimento leva-nos a refletir a respeito de diversos aspectos da vida e obras de Leonardo. Até onde estudar tal cientista nos proporcionará profícuos saberes para nossa formação acadêmica? Há padrões matemáticos em obras de Da Vinci? Quais? Ele optou por utilizá-los ou é tão-somente uma forma de modelarmos (ou efetuarmos leituras de) suas obras? Diante de tais perguntas motivamo-nos a escrever este artigo.

Se tivéssemos que resumir nosso fascínio pelo tema em apenas uma frase, escolheríamos:

\footnotetext{
${ }^{2}$ Dantizg (1970, apud: Brasil, 2014, p.7) afirma que alguns animais também possuem senso numérico, mesmo que rudimentares e restritos, como o caso específico do corvo que consegue identificar se são retirados dois ou mais ovos de seus ninhos.
} 
O homem é único não porque produz ciência, e ele não é único porque produz arte, mas sim porque ciência e arte, igualmente, são expressões da maravilhosa plasticidade de sua mente. (WHITE, 2002, p. 15)

Leonardo Da Vinci consegue realizar tal façanha, juntar ciência com Arte, conseguiu manipular a beleza de suas criações utilizando artífices científicos e, em contrapartida, tornou seus estudos científicos de beleza insofismável aos olhos doutrem, utilizando a Arte. Juntou a curiosidade de aprender com o prazer de criar, resultando em obras de significados extremamente importantes ao desenvolvimento de estudos de outros cientistas de sua e de épocas futuras, produziu obras com significados claros e ao mesmo tempo conseguiu elaborar objetos enigmáticos, que até aos dias contemporâneos iludem e deslumbram, de uma maneira fantástica, mentes e mais mentes, pensadores e mais pensadores.

Assim, nosso objetivo não é estudar toda a vida de Leonardo Da Vinci, mas sim relatar alguns pontos da vida desta figura ímpar, bem como analisar, identificar e apresentar uma possível existência de padrões matemáticos em três de suas mais conhecidas obras - a Mona Lisa, a Dama do Arminho e o Homem Vitruviano - por serem obras que aparecem com frequência em livros didáticos.

Em alguns livros didáticos a sequência de Fibonacci é apresentada de uma maneira bem simples, geralmente através do clássico problema da reprodução dos coelhos quando estudam sequências numéricas e padrões. Então é válido o comprometimento de estudar a presença ou não da sequência de Fibonacci nas obras supracitadas de Da Vinci; bem como a razão áurea, o número de ouro e a espiral logarítmica por estarem interligadas à sequência de Fibonacci (veremos adiante). Assim, propomos não colocar em lados opostos, mas misturarmos, Arte e Matemática em nosso objeto de estudo, tendo em vista que este possa proporcionar contribuições para possíveis aulas de Matemática estabelecendo relações inter ou trans ou pluri ou multidisciplinares ${ }^{3}$.

\footnotetext{
${ }^{3}$ Entenderemos como pluri ou multidisciplinar a justaposição de várias disciplinas sem nenhuma tentativa de síntese. Segundo Weril; D'Ambrosio; Crema (1993) esse é o modelo predominante nas universidades francesas. Quando nos referimos à interdisciplinaridade levamos em conta a síntese de duas ou mais disciplinas, com foco em uma nova ordem, caracterizada por novas enunciações descritivas e novas relações estruturais. Por transdisciplinar tomaremos como o reconhecimento da interdependência de todos os aspectos de uma dada situação a ser estudada, que vai além dos códigos e enunciações típicos de uma disciplina, buscando assim uma visão holística a respeito do problema.
} 


\section{DISCUTINDO ACADEMICAMENTE UM PROCESSO NO TRÂNSITO DA MATEMÁTICA À ARTE}

\subsection{Uma pequena arqueologia da Geometria grega}

Tomemos como ponto de partida algumas linhas para discutirmos um pouco a respeito de uma possível gênese da Geometria, de Pitágoras e dos pitagóricos.

Caraça (1989), ao discutir as relações entre a operação de medição, propriedade privada e Estado, exalta Heródoto ao escrever a respeito da História dos egípcios em seu livro II (Euterpe), das suas Histórias, e refere-se à Geometria da seguinte maneira:

Disseram-me que este rei (Sesóstris) tinha repartido todo o Egito entre os egípcios, e que tinha dado a cada um uma porção igual e rectangular de terra, com a obrigação de pagar por um ano um certo tributo. Que se a porção de algum fosse diminuída pelo rio (Nilo), ele fosse procurar o rei e lhe expusesse o que tinha acontecido à sua terra. Que ao mesmo tempo o rei enviava medidores ao local e fazia medir a terra, a fim de saber de quanto ela estava diminuída e de só fazer pagar o tributo conforme o que tivesse ficado de terra. Eu creio que foi daí que nasceu a Geometria e que depois ela passou aos gregos. (CARAÇA, 1989, p. 32) (ipsis verbis).

A mesma obra destaca ainda que a necessidade de expressão numérica para medição advém das relações do indivíduo para com o Estado, com base na propriedade e na cobrança de tributos, chamando atenção para o fato de que Sesóstris viveu há mais de 4.000 anos. Observemos que dessa forma a gênese do problema da Geometria está presente em relações socioambientais, socioculturais e socioeconômicas. Para os egípcios e babilônios não havia um culto à Matemática como para os gregos. Eles a tomavam como ferramenta de resolução de problemas práticos. Tanto que: 
Pode-se dizer, parece que sem qualquer sombra de dúvida, que o conhecimento matemático tanto egípcio quanto o babilônico - este, sabemos hoje graças ao trabalho de Otto Neugebauer, bem mais refinado do que aquele - tinha a experiência como critério de verdade.

Os gregos herdaram, assim nos diz a tradição, tal conhecimento. Mas, o que satisfazia egípcios e babilônios não bastou para contentar a exigência grega. Com os matemáticos da Grécia, a razão suplanta e empeiria como critério e verdade e a matemática ganha características de uma ciência dedutiva. (BICUDO, 2009, p. 77).

Tais relações com a Matemática (mística para os gregos e prática para egípcios e babilônios) podem ser observadas também no seguinte texto:

Os autores gregos não deixaram de manifestar seu respeito pela sabedoria oriental, e essa sabedoria era acessível a todos que pudessem viajar ao Egito e à Babilônia. Há também evidências internas de uma conexão com o Oriente. 0 misticismo grego primitivo em matemática deixa transparecer uma forte influência oriental e escritos gregos mostram uma perpetuação helênica da tradição mais aritmética do Oriente. Há também fortes elos ligando a astronomia grega à Mesopotâmia. (EVES, 2004, p.96)

Chaves (2004), ao tratar de uma das técnicas de rejeição do discurso, atenta para o fato de que, se por um lado Pitágoras atraiu muitos adeptos e fora merecedor de muitos comentários pelos seus feitos como geômetra, por suas concepções filosóficas, pelo conteúdo aritmético de sua doutrina, ou ainda por suas ambições políticas ${ }^{4}$, por outro lado, o mesmo atraiu muitos desafetos, principalmente Policrates - o tirano de Samos - e Cílon (que acabou apropriando-se do seu livro secreto A palavra Sagrada - Hirós logos - e expôs à multidão trechos da obra roubada, demostrando que o catecismo religioso dos pitagóricos atentava contra a liberdade). Além disso, a credibilidade de Pitágoras também fora colocada à prova quando da crise da incomensurabilidade,

\footnotetext{
${ }^{4}$ Para Schuré (1962 - apud Chaves, 2004, p. 38), Pitágoras queria “...à frente do Estado um governo científico, menos misterioso, mas colocado tão alto como o sacerdócio egípcio... Para ele, saber é poder." Paradoxalmente, talvez seja este um vestígio da gênese do mito positivista da cientificidade (o saber gera poder), da ideologia da competência (quem sabe mais pode mandar e a quem não tem conhecimento cabe obedecer), mas também a negação do mito da neutralidade dos homens do conhecimento.
} 
visto que o lado e a diagonal de um quadrado são grandezas incomensuráveis e, para a doutrina pitagórica,

\begin{abstract}
"tudo é número", ou seja, tudo podia ser explicado através dos números (inteiros) e suas razões (números racionais). Acreditava-se também que dados dois segmentos quaisquer eles eram sempre comensuráveis, i.e., que existia um terceiro segmento, menor que os dois primeiros, tal que cada um deles era múltiplo inteiro do menor. Em termos modernos, se $a$ e $b$ são os comprimentos dos dois segmentos, então existe um segmento de comprimento $c$ e dois inteiros $m$ e $n$ tais que $a=m c$ e $b=n c$. Daí conclui-se que $a / b=m / n$. Muitas das demonstrações à época eram baseadas neste fato (MOREIRA \& CABRAL, 2011, p. 35).
\end{abstract}

Consideremos, pois, o que Eves (2004, p. 103) denomina de unânime tradição, com atribuição a Pitágoras da, "descoberta independente do teorema sobre triângulos retângulos hoje universalmente conhecido pelo seu nome - que o quadrado sobre a hipotenusa de um triângulo retângulo é igual à soma dos quadrados sobre os catetos." (ipsis verbis).

Eis que surge o problema! Qual o valor da diagonal de um quadrado de lado medindo uma unidade de medida linear qualquer? Prontamente, hoje, dirimíamos $\ell \sqrt{2}$ e que tal resultado é consequência imediata do teorema de Pitágoras 5 . O que dizer se $\sqrt{2}$, bem como os demais irracionais, não era na época conhecido para os gregos? Tal crise (a dos incomensuráveis) graças a Cílon, e seu forte poder argumentativo, surge a partir do que poderíamos considerar senão uma das maiores construções da humanidade, pelo menos a mais popular.

Mas Pitágoras não era apenas geômetra. Além de místico também se dedicava a estudar os números - para muitos seus estudos deu origem à teoria dos números e, para outros, limitou-se a praticar uma Aritmética mística. Vejamos alguns de seus feitos.

\footnotetext{
${ }^{5} \mathrm{O}$ teorema de Pitágoras é apresentado na proposição 47, Livro I, de Os Elementos, de Euclides: Nos triângulos retângulos, o quadrado sobre o lado que se estende sob o ângulo reto é igual aos quadrados sobre os lados que contêm o ângulo reto. (BICUDO, 2009, p.132). Bem como o seu recíproco (proposição 48, Livro I): Caso o quadrado o quadrado sobre um dos lados de um triângulo seja igual aos quadrados dos dois lados restantes do triângulo, o ângulo contido pelos dois lados restantes do triângulo é reto. (BICUDO, 2009, p.134).
} 


\subsubsection{Números pitagóricos em distribuições gnomônicas}

Os gregos da Antiguidade consideravam gnomon (etmologicamente, conhecedor) como uma peça que poderia juntar-se a uma figura da mesma forma, mas de tamanho maior. Se tomarmos a figura 2 a seguir verificaremos que cada gnomon, representado pelo corredor em forma de " $L$ " (refletido) representa um número ímpar da sequência $(1,3,5,7,9,11, \ldots)$. Observemos que cada novo quadrado formado apresenta como resultado a soma dos gnomons que os constituem. Comparemos então a figura 2 com a tabela 1 a seguir.

Figura 1. Representação da distribuição de pontos em forma de quadrado.

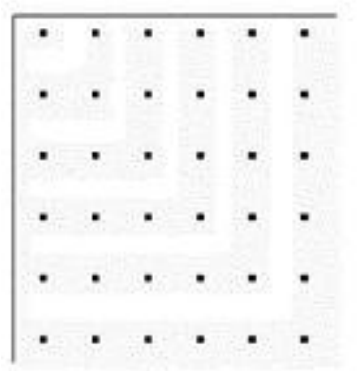

Figura 2. Gnomons que representam a série

$$
1+3+5+7(\ldots)
$$

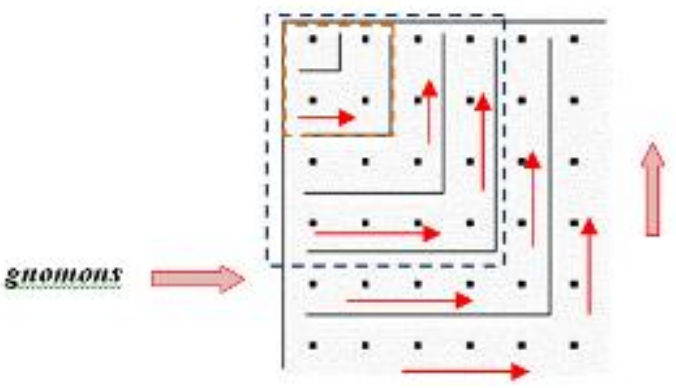

Fonte: Dados da pesquisa.

O terno pitagórico primitivo $(3,4,5)$ gnomonicamente pode ser representado conforme na figura 3 a seguir, visto que:

$$
3^{2}+4^{2}=5^{2} \Rightarrow 5^{2}-3^{2}=4^{2}
$$

Figura 3. Representação de um terno pitagórico na forma de gnomons.

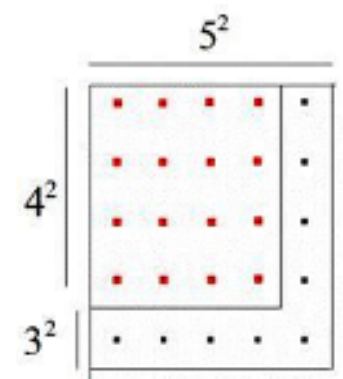

Fonte: Dados da pesquisa. 
Isto é, se do quadrado de 5 por 5 pontos retirarmos o gnomon constituído de 9 pontos, portanto $3^{2}$, ficaremos com um quadrado de 4 por 4 pontos.

Observando cada gnomon na figura 2 é possível construirmos a tabela 1 a seguir e veremos que o 1 gnomon possui 1 elemento. 02 2 gnomon possui 3 elementos e se "juntarmos" com o primeiro formaremos um novo quadrado formado por $1+3=4$ elementos. O 3o gnomon é formado por 5 elementos e se "juntarmos" com o primeiro e o segundo gnomons formaremos um novo quadrado com $1+3+5=9$ elementos.

Tabela 1. Resultado das somas parciais por novos quadrados formados.

\begin{tabular}{|c|c|c|}
\hline Ordem & Adição dos elementos & Soma \\
\hline 1 & 1 & 1 \\
\hline 2 & $1+3$ & 4 \\
\hline 3 & $1+3+5$ & 9 \\
\hline 4 & $1+3+5+7$ & 16 \\
\hline 5 & $1+3+5+7+9$ & 25 \\
\hline 6 & $1+3+5+7+9+11$ & 36 \\
\hline
\end{tabular}

Fonte: Dados da pesquisa.

Analisando algumas relações, entre linhas e colunas da tabela anterior, é possível, por exemplo, destacarmos algumas relações. Verificando linha por linha, por recorrência, na $n$-ésima linha teremos: (i) uma soma de $n$ elementos, (ii) $2 n-1$ elementos no gnomon; (iii) a soma dos $n$ primeiros números ímpares, começando por 1, comparando, linha por linha, a primeira e a terceira colunas podemos verificar que o resultado é o quadrado perfeito correspondente. Ou seja,

$$
1+3+5+7+9+\ldots+2 n-1=n^{2}
$$

que também pode ser ilustrado conforme figura 4 a seguir: 
Figura 4. Representação gnomônica da soma de $n$ primeiros números inteiros positivos ímpares.

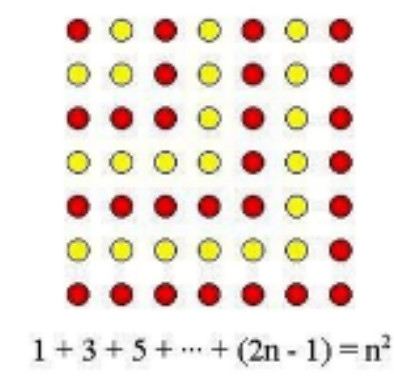

Fonte: Dados da pesquisa.

Assim, podemos generalizar que: a soma de um número qualquer de inteiros ímpares consecutivos, começando com o 1, é um quadrado perfeito. Observemos que não apenas o apelo de utilização das técnicas de cor, mas também a disposição gnomônica, auxilia, senão na constatação, pelo menos na verificação, de que tal soma gera um quadrado perfeito.

A distribuição gnomônica, bem como a organização de números segundo padrões (como os números figurados ${ }^{6}$, por exemplo) constituem-se em argumentos irrefutáveis de que a humanidade prima por tentar representar o universo, a vida, os objetos, a música, as expressões da sua cultura segundo uma organização ou decodificação matemática. Daí a concepção platônica de que "Deus é o grande geomêtra. Deus geometriza sem cessar." Assim, efetuar leituras matemáticas do mundo não é artifício da modernidade, mas peculiar aos seres humanos.

\subsubsection{A sequência de Fibonacci ${ }^{7}$}

Foi em Liber Abacci (1202) que Fibonacci apresentou a sequência que levou seu nome, embora tal sequência já tivesse sido descrita por matemáticos indianos. O problema de Fibonacci consta de

\footnotetext{
${ }^{6}$ Os pitagóricos estabeleceram o que seria a gênese da relação entre a Aritmética e a Geometria, ao relacionarem números a formas. Mais ainda, exaltaram e estudaram propriedades dos números e da Aritmética juntamente com a Geometria, a Música e a Astronomia, que constituíam as artes liberais básicas do programa educacional pitagórico, o quadrivium. Assim desenvolveram os números figurados originados entre os membros mais antigos da academia pitagórica, segundo Eves (2004, p. 100) “Esses números, que expressam o número de pontos em certas configurações geométricas, representam a nomenclatura números triangulares, números quadrados, números pentagonais e assim por diante.".

${ }^{7}$ Leonardo de Pisa ( \pm 1175 - \pm 1250$)$ nasceu em Pisa. Viajou várias vezes ao Oriente e ao Norte de África, onde o sistema de numeração hindu-arábico era já largamente usado. Teve acesso à obra de al-Khwarismi e assimilou numerosas informações aritméticas e algébricas compilando-as em seu livros que influenciaram a introdução do sistema de numeração hindu-arábico na Europa. Estudou as operações elementares, assim como os números naturais, a decomposição de números em fatores primos, as frações e as equações dentre outros.
} 
uma única pergunta: Quantos pares de coelhos podem ser gerados de um par de coelhos em um ano?

Como hipóteses para solução ele considerou: (i) a cada mês ocorre o nascimento de um casal; (ii) um casal começa a reproduzir ao completar dois meses de vida. Assim, observemos a figura a seguir.

Figura 5. Geração de pares de coelhos segundo as hipóteses do Problema de Fibonacci.

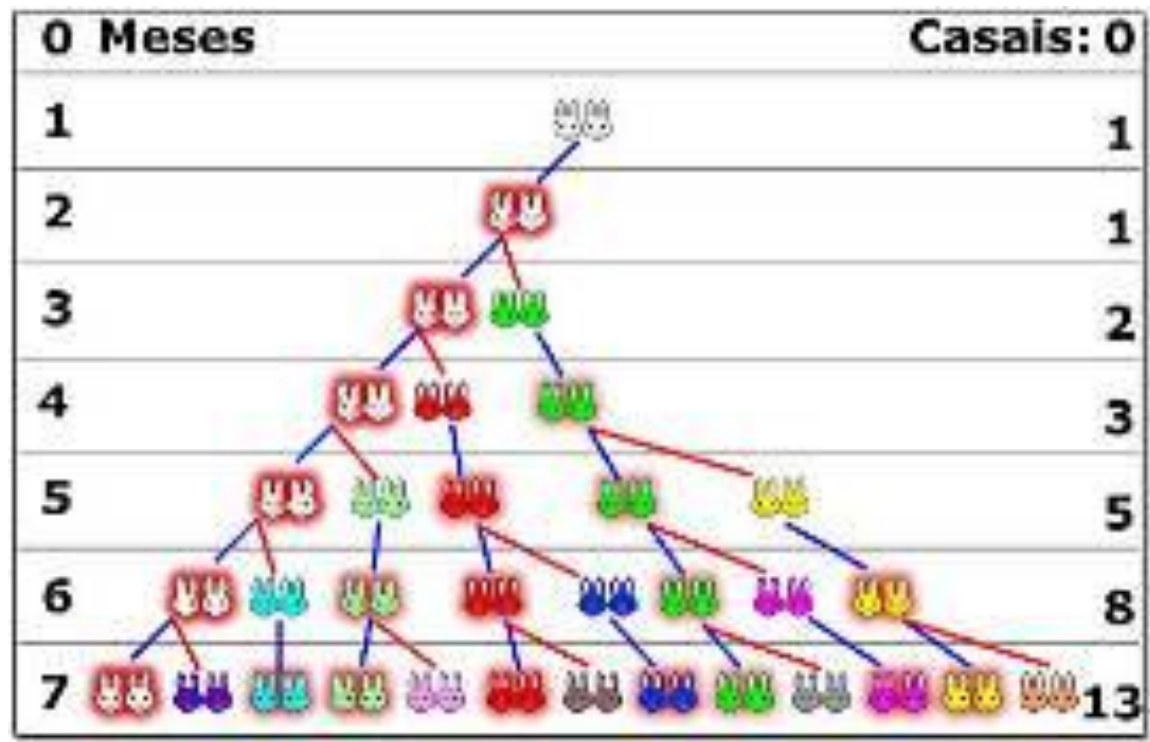

Fonte: CHAVES, 2011 - 5o Seminário do Programa de Iniciação Científica do IFG

Vejamos que, em colunas, temos:

1

$1=1+0$

$2=1+1$

$3=1+2$

$5=2+3$

$8=3+5$

$13=5+8$

$21=8+13$ 
Por recorrência podemos verificar que cada termo desta sequência (a partir do 3으) é a soma de outros dois termos que o antecedem. Logo, em um ano a sequência gerada foi:

Uma possível configuração de gnomons a considerar relaciona a sequência de Fibonacci com a sequência de retângulos áureos que formará uma espiral logarítmica (Cf. figuras 6 e 7). Para tal, na figura 6, basta seguir o esquema de setas apresentadas, onde o comprimento de cada segmento representa um termo da sequência e ao partir de um segmento para outro rotacionamos em 90 은 no sentido anti-horário.

Dessa forma, na figura 6, temos: (a) um quadrado de lado 1; (b) um retângulo de dimensões 1 e 2; (c) um retângulo de dimensões 2 e 3; (d) um retângulo de dimensões 3 e 5; (e) um retângulo de dimensões 5 e 8; (f) um retângulo de dimensões 8 e 13.

Figura 6. termos da sequência de Fibonacci a partir dos gnomons.

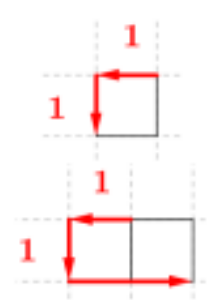

2

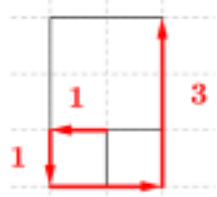

(a)

(b)

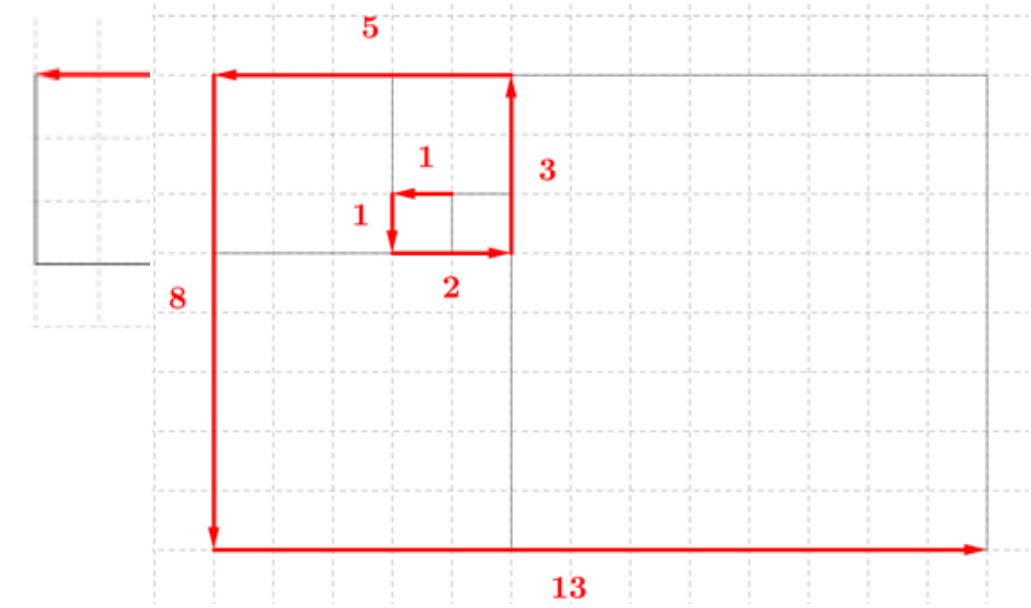

Fonte: Dados da pesquisa. (e)

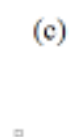


de base e 8 de altura; (viii) um quadrado de lado 8; (ix) um retângulo de dimensões 13 de base e 8 de altura.

Figura 7. Espiral logarítmica.

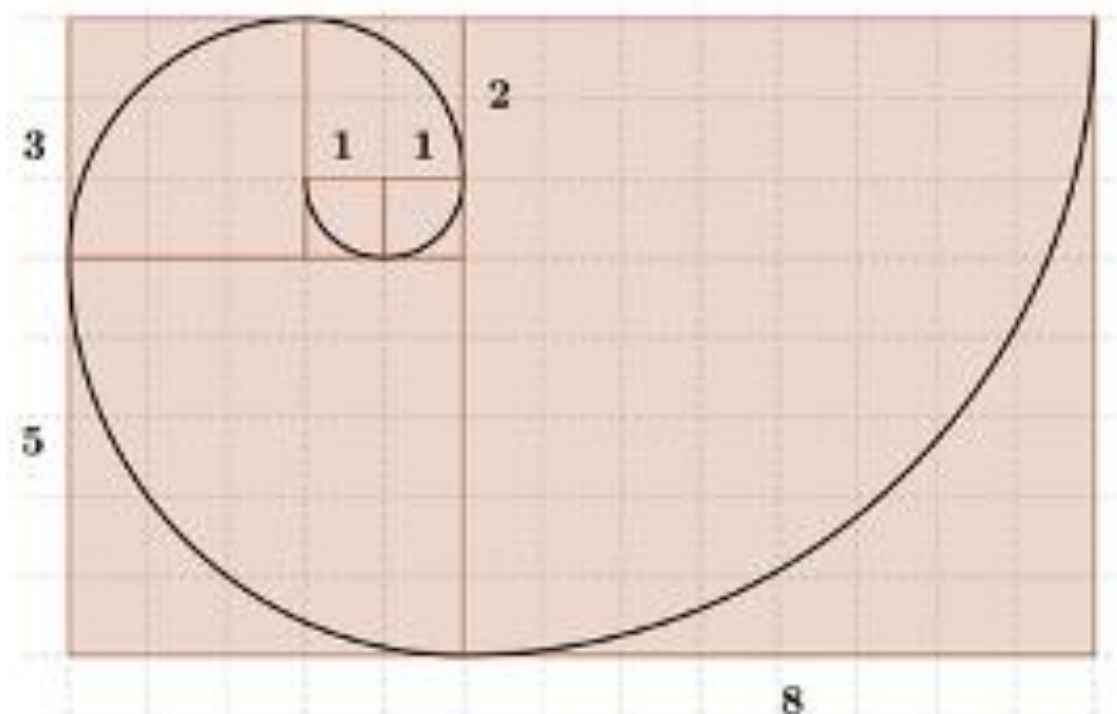

Fonte: Dados da pesquisa.

Já mencionamos que a busca de padrões é intrínseca ao ser humano, bem como a alguns animais. É da natureza humana identificar padrões para efetuar leituras do mundo e em o trânsito entre a produção de significados a partir de padrões geométricos é mais peculiar do que se imagina; tanto que, ao modelarmos, partimos sempre do modelo mais simples, e a busca de simplificação é peculiar à tentativa de transformar um conjunto de dados numéricos em um gráfico ou padrão geométrico.

Ao tomarmos a sequência de Fibonacci, não relacionamos todos os possíveis significados a serem produzidos para esse objeto, mas sim o que em um contexto preciso se diz efetivamente. Logo, parafraseando Cezar (2014, p. 34), as leituras que efetuamos nos permitem refletir a respeito do que possivelmente venha a ser uma sequência de Fibonacci, por meio de construções criadas por outras pessoas, que tomamos como verdade, porém não necessariamente únicas. As verdades que produzimos e enunciaremos a partir do que nos é enunciado estão relacionadas com o contexto que estas enunciações estão inseridas e com os significados que produzimos a elas. 


\subsubsection{O número de Ouro}

O Livro VI, de Os Elementos de Euclides, na definição 3, diz: Uma reta é dita estar cortada em extrema e média razão, quando como a toda esteja para o maior segmento, assim o maior para o menor. (BICUDO, 2009, p. 231). Comumente os compêndios de Desenho Geométrico, por exemplo, definem média e extrema razão (segmento áureo) como:

Dividir um segmento em média e extrema razão consiste em dividi-lo em dois outros segmentos tais que o maior seja a média proporcional entre o segmento dado e o menor. O segmento maior denomina-se segmento áureo (significa 'segmento de ouro', considerado pelos antigos gregos como segmento da medida perfeita) (PINTO, 1991, p. 93).

Isto é, dado o segmento $\overline{A B}$ de extremidades em $A$ e $B$, o ponto $X$, denominado ponto de ouro, é tal que:

Figura 8. Divisão de um segmento em média e extrema razão (segmento áureo)

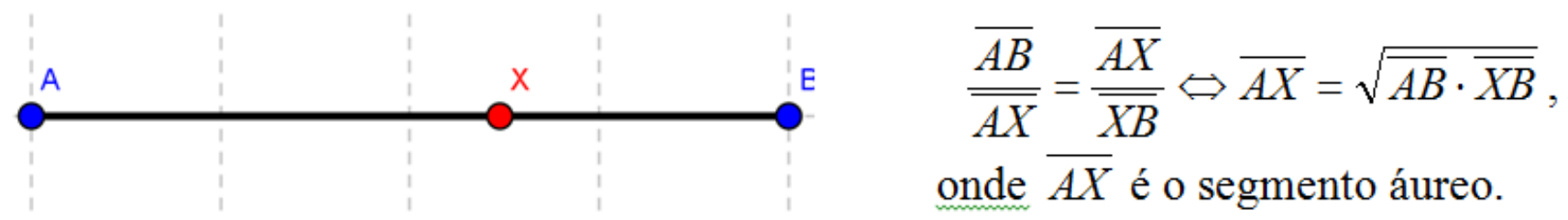

Fonte: Dados da pesquisa.

Ainda, Pinto (1991, p. 94) destaca, na forma de receituário, o seguinte processo para determinar um ponto $X$ que divide um segmento de extremidades $\overline{A B}$ em média e extrema razão: (i) traçamos uma semicircunferência (Cf. figura 19) de centro em $A$ e extremidade em $B$; (ii) prolongamos o segmento $\overline{A B}$ e determinamos o diâmetro $\overline{C B}$; (iii) traçamos uma perpendicular a $\overline{C B}$ passando pelo ponto $A$ e encontramos o raio $\overline{A D}$; (iv) determinamos $M$, ponto médio do segmento $\overline{C A}$; (v) traçamos um arco de circunferência com centro em $M$ e extremidade em $D$ até encontramos o segmento $\overline{A B}$ e determinamos o ponto $X$ que divide o segmento $\overline{A B}$ em média $e$ extrema razão; (vi) o segmento $\overline{A X}$ é o segmento áureo, visto que $\frac{\overline{A B}}{\overline{A X}}=\frac{\overline{A X}}{\overline{X B}}$. 
Figura 9. Técnica de determinação do ponto que divide um segmento em média e extrema razão.

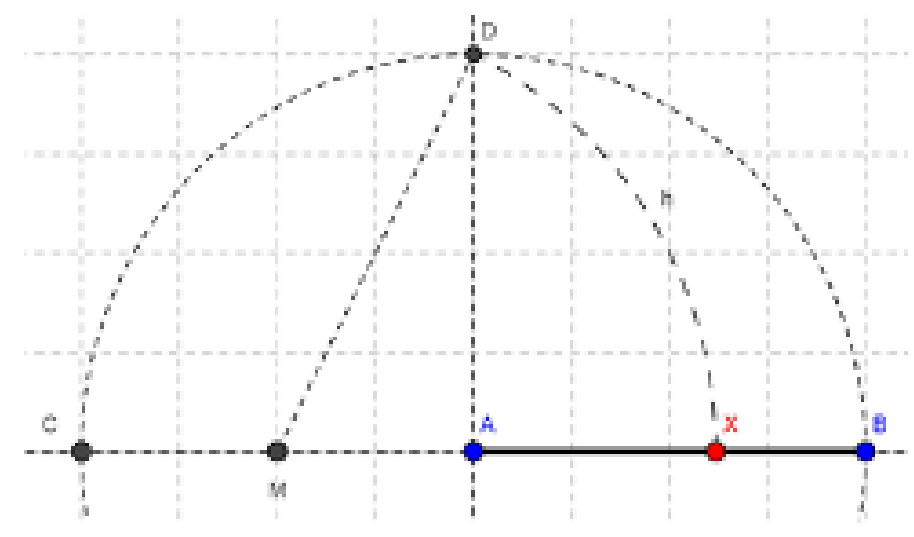

Fonte: Dados da pesquisa.

Se bem observarmos $\overline{A B}=\overline{A D}=r$, raio do semicírculo, e $\overline{M A}=\frac{r}{2}$. Vejamos que $\overline{M D}=R$ é o raio do arco $D M X$ e, consequentemente, $\overline{M X}=\overline{M A}+\overline{A X}$; isto é,

$$
R=\frac{r}{2}+x \Rightarrow x=R-\frac{r}{2}
$$

Se tomarmos o triângulo retângulo $\triangle M A D$ e aplicarmos o teorema de Pitágoras teremos que:

$$
R=\frac{r \sqrt{5}}{2}
$$

De (4) e (5) podemos concluir que:

$$
x=\frac{r \cdot(\sqrt{5}-1)}{2}=r \cdot 0,6180339887 \ldots
$$

Agora, como $\overline{M X}=\overline{M A}+\overline{A X}$ de (4) e (6), temos que

$$
\overline{M X}=R=r \cdot 1,6180339887 \ldots=r \cdot \phi
$$


Já Brandão (2014) conjectura que os pitagóricos utilizaram um processo geométrico para determinar a média e extrema razão de um segmento; isto é, para determinar o ponto áureo em um segmento dado.

A forma tradicional, encontrada no livro Os elementos de Euclides, de resolução geométrica desta proporção é a seguinte: Dado o segmento $A B$, constroi-se o quadrado $A B A^{\prime} B^{\prime}$; constroi-se $M$ como o ponto médio de $A A^{\prime}$. Prolonga-se o segmento $A A^{\prime}$ e constroi-se a circunferência de centro $M$ e raio $M B^{\prime}$, acha-se o ponto $C$ de interseção da circunferência com a semi-reta $A A^{\prime}$; constroi-se o quadrado de lado $A^{\prime} C$. O prolongamento do lado $D D^{\prime}$ determina o ponto $X$ em $A B$ que seciona o segmento na razão desejada.

Figura 10. Demonstração segundo (BRANDÃO, 2014, ipsis verbis).

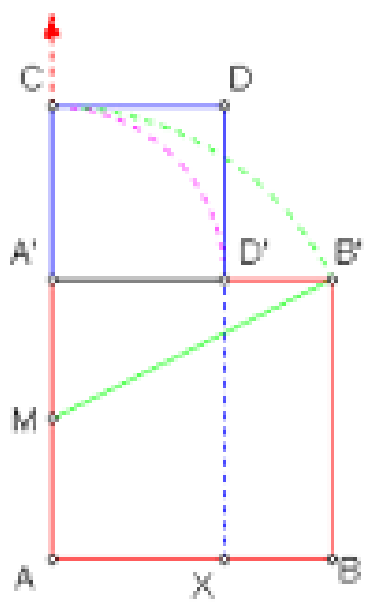

Fonte: <http://www.matematica.br/historia/saurea.html>.

Para determinarmos a medida do segmento áureo $\overline{A X}=x$, consideremos o segmento $\overline{A B}=a$ e $\overline{M C}=y$. Observemos que $\overline{M C}=\overline{M B^{\prime}}=y$, por ser raio do arco de circunferência $M C B^{\prime}$. Como $M$ é ponto médio do lado do quadrado, temos $\overline{A^{\prime} M}=\frac{a}{2}$. Aplicando o teorema de Pitágoras no triângulo retângulo $\Delta A^{\prime} M B^{\prime}$, temos:

$$
y^{2}=a^{2}+\frac{a^{2}}{4} \Rightarrow y=\frac{a \sqrt{5}}{2}
$$


Mas, como $A^{\prime} C D D^{\prime}$ é um quadrado, temos que $\overline{A X}=x=y-\frac{a}{2}$. Daí, se considerarmos $a=1$ e de (8):

$$
\overline{A X}=x=\frac{\sqrt{5}-1}{2}=\frac{1}{\phi}=0,6180339887 \ldots
$$

Isso significa que o segmento áureo equivale a aproximadamente $61,8 \%$ do comprimento total do segmento, mas,

$$
\frac{1}{\phi}=0,6180339887 \ldots \Rightarrow \frac{1}{0,6180339887 \ldots}=\phi \Rightarrow \phi=1,6180339887 \ldots
$$

denominado número de ouro.

Para construirmos um retângulo áureo, seguimos os seguintes passos: (i) construímos o quadrado $A B C D$; (ii) determinamos o ponto médio $M$ do lado $\overline{A B}$; (iii) fixamos o compasso com centro em $M$ e extremidade em $C$ e traçamos até a reta suporte de $\overline{A B}$ o arco de circunferência $C M X$, onde $X$ é a extremidade da base do retângulo áureo AXID.

Figura 11. Construção do retângulo áureo a partir de um quadrado.

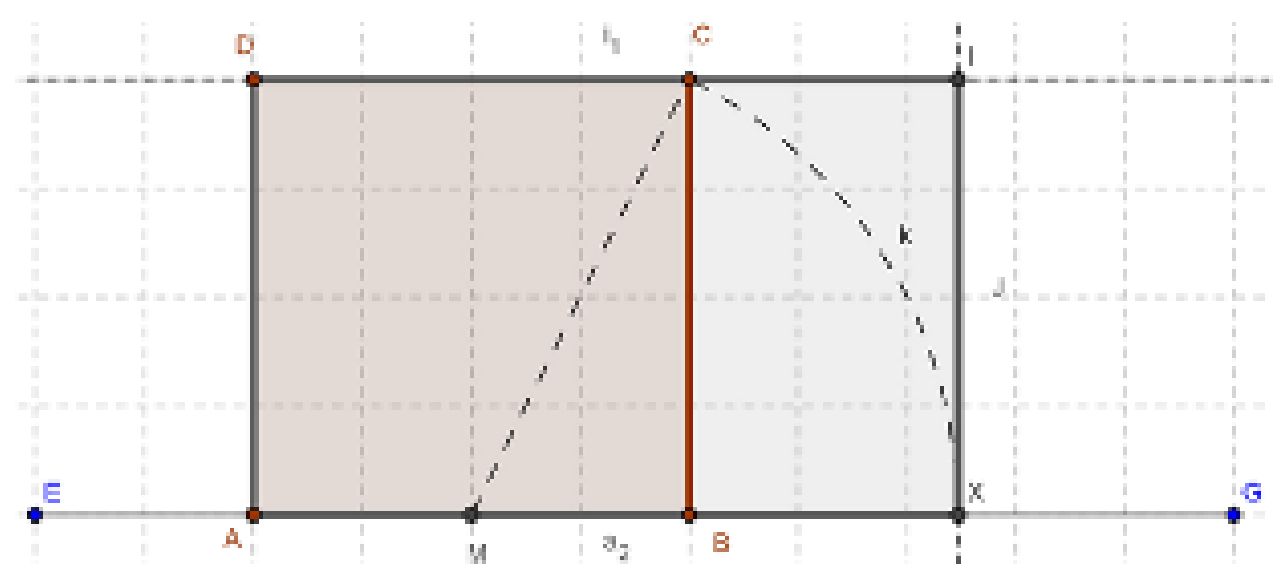

Fonte: Dados da Pesquisa 
Assim, em cada retângulo formado a relação entre base e altura está diretamente associada à razão áurea, pois (no caso da figura 11) $\overline{A X}, \overline{A B}$ e $\overline{X B}$ estão em média e extrema razão. Vejamos que na figura a seguir (figura 12) temos sucessivos retângulos áureos gerando quadrados de lados $1,1,2,3,5,8, \ldots$ que são os termos da Sequência de Fibonacci. Eis então uma relação entre tal sequência e razão áurea.

Figura 12. A Sequência de Fibonacci presente no retângulo áureo.

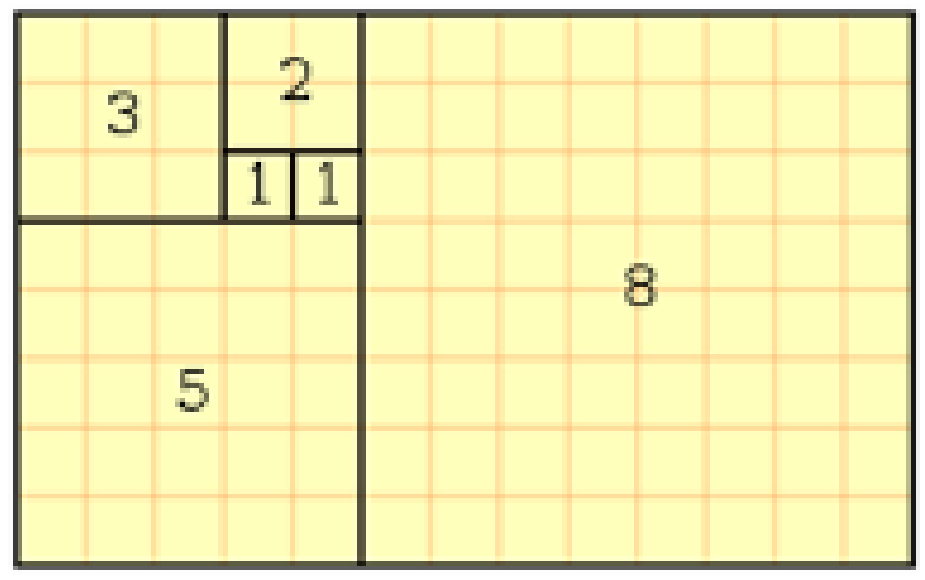

Fonte: CHAVES, 2011 - 5o Seminário do Programa de Iniciação Científica do IFG

Ainda a respeito da Sequência de Fibonacci, observemos o que acontece quando tomamos dois termos consecutivos e dividimos cada termo pelo seu antecedente.

Tabela 2. Razão dos termos da Sequência de Fibonacci.

\begin{tabular}{|c|c|c|c|}
\hline MES & PARES & & \\
\hline 1 & 1 & & \\
\hline 2 & 1 & $1 / 1$ & 1 \\
\hline 3 & 2 & $2 / 1$ & 2 \\
\hline 4 & 3 & $3 / 2$ & 1,5 \\
\hline 5 & 5 & $5 / 3$ & 1,666667 \\
\hline 6 & 8 & $8 / 5$ & 1,6 \\
\hline 2 & 13 & $13 / 8$ & 1,625 \\
\hline 8 & 21 & $21 / 13$ & 1,615385 \\
\hline 9 & 34 & $34 / 21$ & 1,619048 \\
\hline 10 & 55 & $55 / 34$ & 1,617647 \\
\hline 11 & 89 & $89 / 55$ & 1,618182 \\
\hline 12 & 144 & $144 / 89$ & 1,617978 \\
\hline
\end{tabular}

Fonte: Dados da pesquisa.
Figura 13. Convergência das sucessivas razões entre termos consecutivos da Sequência de Fibonacci.

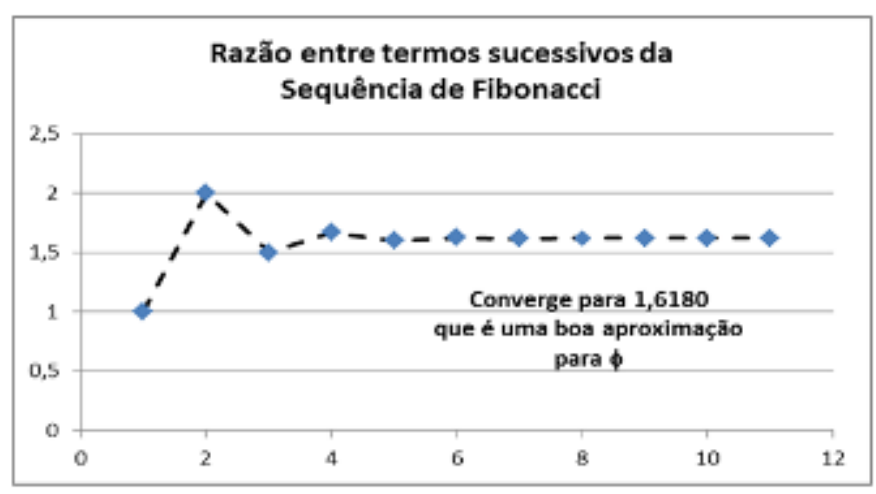


Vejamos que há convergência (gráfico da figura 13) com uma boa aproximação para o número phi ( $\phi)$ ou número de ouro.

Consideremos agora o pentágono regular $A B C D E$ a seguir e tomemos a diagonal $C E$. Observemos que o ponto $F$ é obtido pela interseção da diagonal $C E$ com a diagonal $A D$ bem como o ponto $G$ é a interseção da diagonal $C E$ com a diagonal $B D$.

Figura 14. Pentragrama pitagórico.

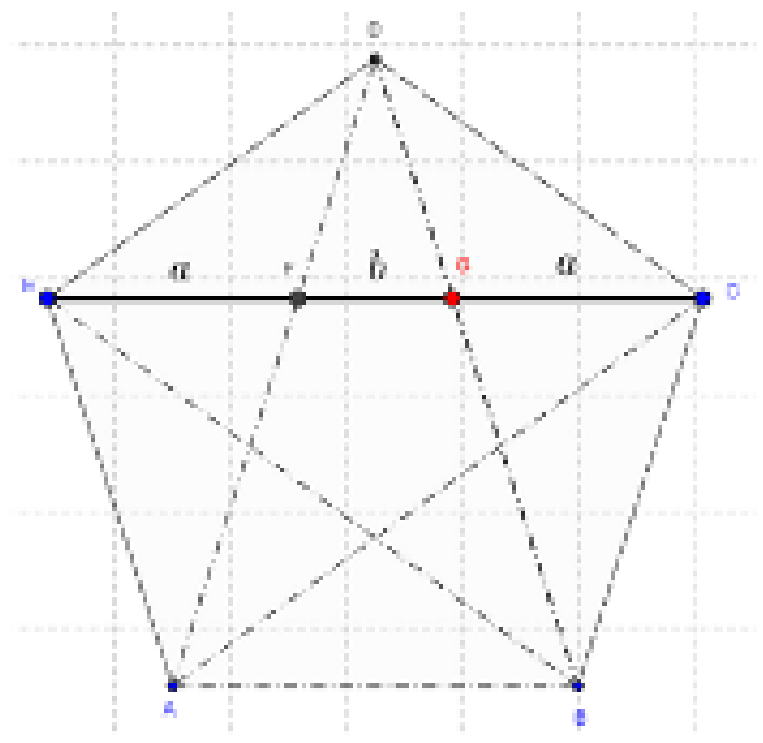

Fonte: Dados da pesquisa.

Como $A B C D E$ é regular, o ângulo $C D E$ mede 108o e pela lei angular de Tales é verificável que os ângulos congruentes $D E F \equiv E D F \equiv F D G \equiv G D C=36^{\circ}$. Analogamente, os ângulos congruentes $E D G \equiv D G E \equiv D F G \equiv D G F=72^{\circ}$. Assim os triângulos $\triangle D E G$ e $\triangle F D G$ são semelhantes e, consequentemente,

$$
\frac{\overline{D G}}{\overline{F G}}=\frac{\overline{E G}}{\overline{D F}}
$$

Seja $\overline{D G} \equiv \overline{D F}=a, \overline{E G}=a+b$ e $\overline{F G}=b$. De (11) temos então:

$$
\frac{a}{b}=\frac{a+b}{a} \Rightarrow a^{2}-b a-b^{2}=0 \Rightarrow a=\frac{b+\sqrt{b^{2}+4 b^{2}}}{2} \Rightarrow a=b \cdot\left(\frac{1+\sqrt{5}}{2}\right)
$$


Isto é, de (12) temos que

$$
a=b \cdot \phi
$$

Assim, observemos que

$$
\frac{\overline{E C}}{\overline{E G}}=\frac{\overline{E G}}{\overline{C G}} \Rightarrow \frac{2 a+b}{a+b}=\frac{a+b}{a} \Rightarrow a^{2}-b a-b^{2}=0
$$

Logo, assim como em (12) $\overline{E G}$ é o segmento áureo de $\overline{C E}$ e, consequentemente, $G$ é o ponto de ouro do segmento $\overline{E G}$.

\subsection{Um pouco da vida de Leonardo Da Vinci}

No final do século XV e início do século XVI, nos deparamos com uma figura interessante. Artista, filósofo, físico, engenheiro, inventor, arquiteto, escultor, cartógrafo, geólogo, astrônomo, anatomista, compositor, poeta, cozinheiro, e matemático. Seu nome? Leonardo Da Vinci, filho do notório advogado Piero de Antonio Da Vinci, e da camponesa Catarina. Viveu em uma época propícia para desenvolver seus talentos: a Renascença. Em poucas linhas o pensador Giorgio Vasari define Leonardo: "Cada uma de suas ações é tão divina que, deixando atrás de si todos os outros homens, expressamente se faz conhecer como uma coisa concedida por Deus" (BAGNI; D'AMORE, 2011, p. 1). Para Freud, Leonardo é "um homem que acordou muito cedo da escuridão enquanto outros homens dormiam." (BAGNI; D'AMORE, 2011, p. 1).

No que tange à Matemática, Leonardo, amante da Geometria ${ }^{8}$ dedicou-se ao trabalho com figuras geométricas. Sua realização mais notável neste campo é o poliédrico, conjunto de ilustrações (Cf.

\footnotetext{
${ }^{8}$ Em Atalay (2008, p. 144): "Espalhadas entre os manuscritos de Leonardo da Vinci, junto com desenhos, anotações, rabiscos e cálculos, há também diversas criações poliédricas, fruto do que Leonardo denominava sua 'recreação geométrica'. Com infinitas possibilidades de variação, esses poliedros regulares e semirregulares parecem ter fascinado Leonardo".
} 
figuras 15 a 17) nas obras "Summa de Arithmetica, Geometrica, proportioni et proportionalita" (1494) e "De divina proportione" (1509) de Luca Pacioli 9

Figura 15: O termo Ycocedron Planus Abscisus na placa título significa icosaedro truncado.
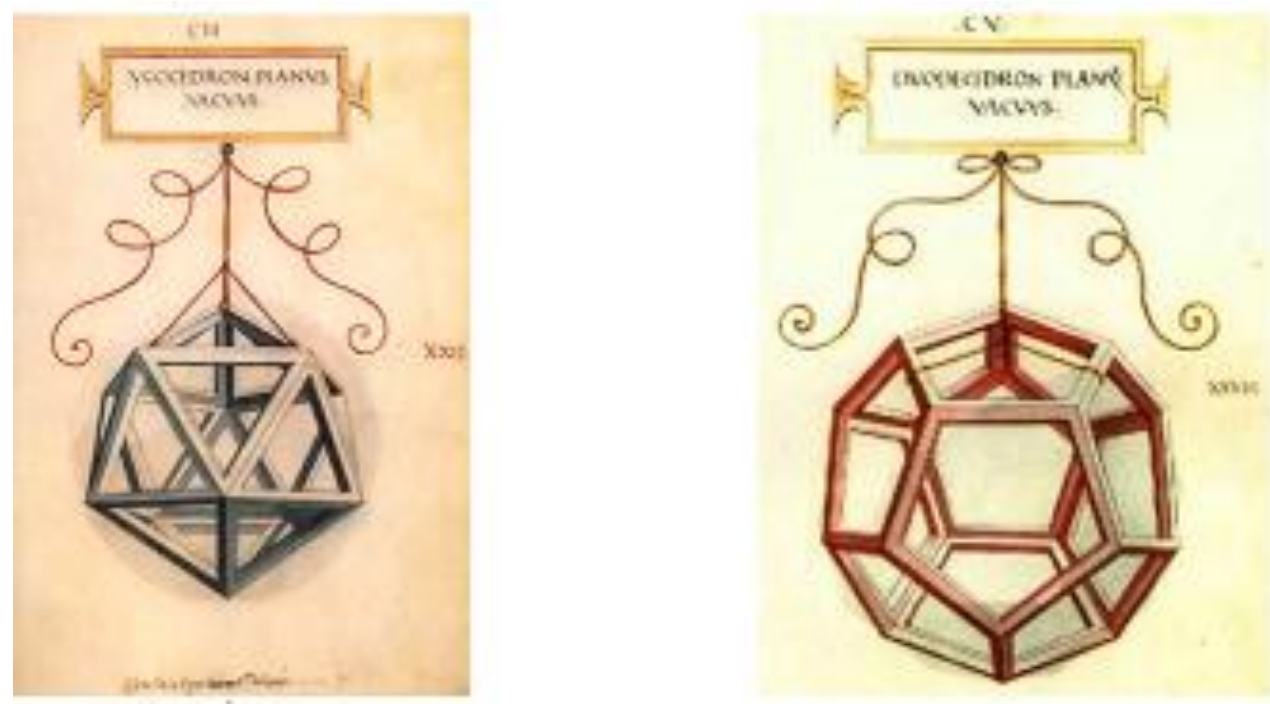

Fonte: <http://jonasportal.blogspot.com.br/2010/03/os-poliedros-de-leonardo-da-

vinci.html>.

\footnotetext{
${ }^{9}$ Luca Bartolomeo de Pacioli $(\underline{1445}$ - 1517), monge franciscano e célebre matemático italiano. Em $\underline{1475}$, tornou-se o primeiro professor de matemática da Universidade de Perugia. Pacioli tornou-se famoso devido a um capítulo deste livro que tratava sobre contabilidade: Particulario de computies et scripturis. Nesta seção do livro, Pacioli foi o primeiro a descrever a contabilidade de dupla entrada, conhecido como método veneziano (el modo de Vinegia) ou ainda "método das partidas dobradas", por isso é considerado o pai da contabilidade moderna. Esse sistema foi introduzido em 1494, em um tratado matemático o qual o mérito fora atribuído a Fibonacci, que por sua vez, introduzira tal metodologia 3 séculos antes, em sua obra Summa.
} 
Figura 16. Os Poliedros de Leonardo da Vinci - desenhos feitos manualmente com admirável perfeição.
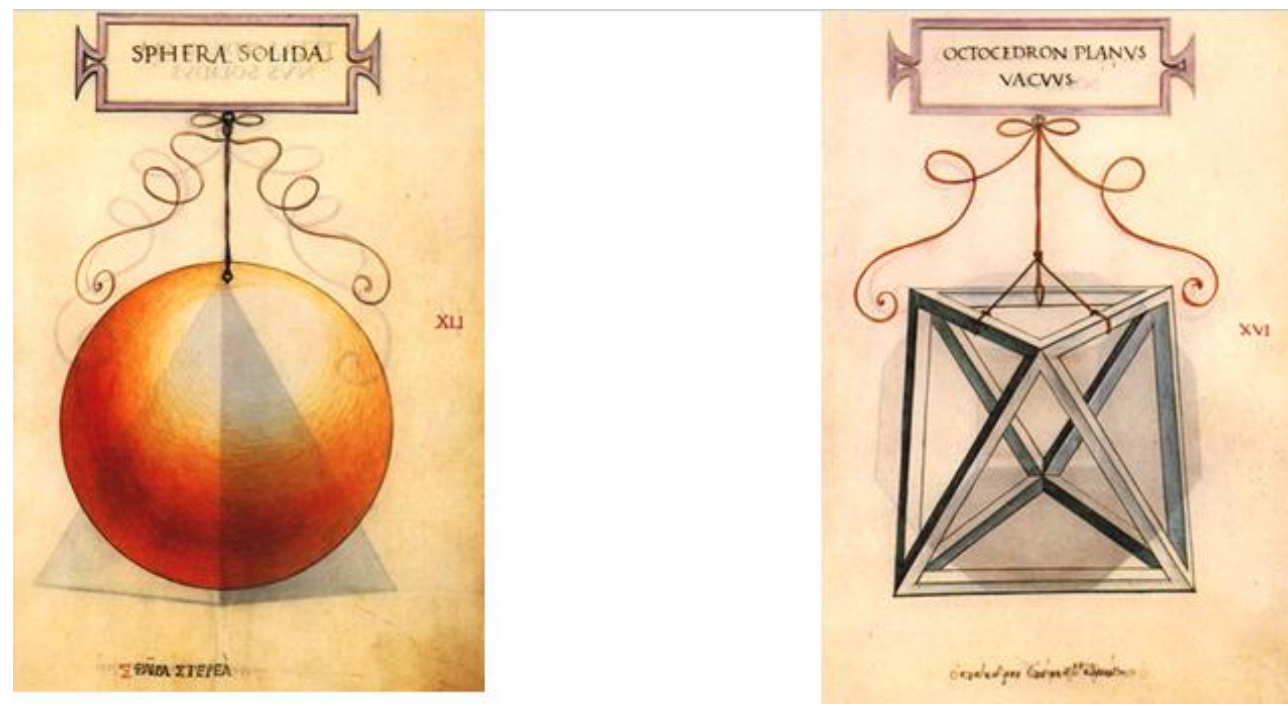

Fonte: <http://jonasportal.blogspot.com.br/2010/03/os-poliedros-de-leonardo-da-vinci.html>.

Figura 17. llustrações de Da Vinci em De divina proportione.

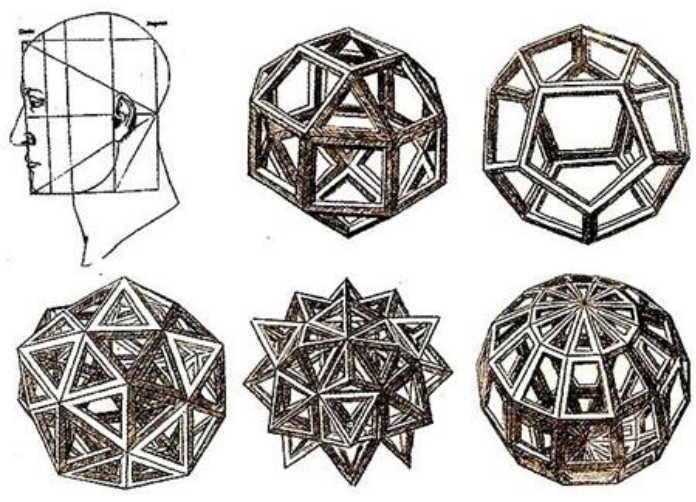

Fonte: ATALAY, 2008, p. 115.

Em De divina proportione além de texto explicativo, há 60 ilustrações, das quais vários poliedros bem como o desenho de um novo tipo de letra impressa - caracteres vitruvianos. É possível também verificar a presença de uma figura onde faz análise das proporções de um rosto humano tomado de perfil; em tal gravura é traçado um triângulo equilátero com um dos vértices localizado na base do crânio e base oposta tangenciando o perfil (Cf. figura 17). 
Da Vinci, que além de amigo também foi aluno de Pacioli, que nutria fascínio pela Geometria ${ }^{10}$. Mas apesar de sua genialidade e desenvoltura com a Geometria, afirma Bagni; D’Amore (2011, p. 64) que "Leonardo não parecia sentir-se à vontade com as frações." O que pode ser comprovado no verso da folha 191, do Código Atlântico ${ }^{11}$.

\subsection{Padrões matemáticos nas obras de Da Vinci}

Os escritos mais importantes de Leonardo apontam sua relação com a Matemática. Suas coleções mais importantes são 10 códigos, dos quais envolvendo Matemática são: Código Atlântico (14781518); Código Arundel (1478-1518); Códigos de Madri (1490-1505); Códigos do Instituto de França; Códigos Foster (1493-1505).

As considerações geométricas e as construções geométricas exatas que foram encontradas até agora no famoso Código Atlântico e nos outros manuscritos impressos não são suficientes, embora tudo que neles se leia seja original, para considerar Leonardo entre aqueles que souberam acrescentar alguma página à geometria herdada dos gregos (a única conhecida em seu tempo). Além disso, a ideia, manifestada por ele, de obter a retificação da circunferência fazendo escorregar uma roda sobre uma haste reta, confirma a opinião de que ele se interessava por geometria apenas na medida em que essa ciência resultava ser útil aos pintores e aos arquitetos. É uma conclusão que se confirma nas aplicações por ele realizadas de algumas lúnudas de Hipócrates (...) à quadratura de figuras complicadas, esteticamente admiráveis, mas carentes de valor científico (LORIA, 1929-1933, p. 263 apud. BAGNI; D'AMORE, 2011, p. 62).

Pelo que expusemos até então é possível ver que, mais do que verificar a existência de padrões nas obras de Da Vinci, é incontestável o quanto Leonardo produz Matemática e mesmo que os céticos aleguem ser aquém da Matemática que hoje se conhece, lembramos ser muito além da Matemática produzida na sua época.

\footnotetext{
10 "O interesse pela geometria, já tão presente em Leonardo, cresce imensamente à medida que Luca (Pacioli) a revela para ele." (BAGNI; D'AMORE, 2011, p. 62 - grifo nosso).

${ }^{11}$ Ao tratar da obra de Leonardo Da Vinci adota-se o nome de Código para cada uma de suas coleções. Trata-se de cerca de 5.000 páginas de apontamentos que possuem a peculiar característica de terem sido grafados da direita para esquerda, elemento característico desse notório canhoto.
} 
Sua admiração pela razão áurea é apresentada por Bagni; D’Amore (2011):

A geometria do nosso protagonista torna-se mais culta, os problemas propostos são quase sempre extraídos da obra de Pacioli, com frequência, por sua vez, extraídos de Euclides. Leonardo apaixona-se pela razão áurea que lhe é apresentada por Pacioli, à qual dá o nome de 'divina proporção' (BAGNI; D'AMORE, 2011, p. 72).

Mas o próprio Leonardo declara essa admiração pela teoria das proporções (incluindo a divina proporção) ao discorrer sobre a anatomia humana com o propósito de tratar suas obras. Mesmo que não tenha sido o primeiro a descrever as proporções ideais do rosto com obsessiva exatidão, escreveu mais de 800 páginas a respeito da proporcionalidade do rosto e depois passado ao resto do corpo, como pode ser observado no Código Atlântico e no Código Windsor.

A DIVINA PROPORÇÃO E A ANATOMIA HUMANA - A distância entre a fenda da boca e base do nariz é um sétimo do rosto [...]. A distância entre a boca e abaixo do queixo será um quarto do rosto, assemelhando-se à largura da boca [...]. A distância entre o queixo e a base do nariz será metade do rosto. Se dividirmos em quatro partes iguais o comprimento total do nariz (ou seja, desde a ponta até a junção com as sobrancelhas), veremos que a parte inferior corresponde à distância entre acima das narinas e abaixo da ponta do nariz; a parte superior, à distância entre o duto lacrimal e o início das sobrancelhas; e as duas partes intermediárias, à distância entre os dois cantos de cada olho (DA VINCI apu. ATALAY, 2008, p. 131).

Veremos em figuras adiante que Da Vinci lançou mão de recursos que envolvem a retângulos áureos. Já vimos anteriormente a relação entre retângulos áureos e a sequência de Fibonacci, mas é Atalay (2008) que relaciona Fibonacci a Da Vinci: 
[...] há entre a matemática, a estética e a ciência uma ligação mais ampla que nos leva a pôr os dois Leonardos (o Da Vinci e o Fibonacci) sob a mesma égide intelectual. Mas, no fim das contas, temos também a poderosa imagem de afluentes intelectuais cujas nascentes eram muito anteriores (no antigo Egito, na Índia, na Babilônia e na Grécia clássica), mas cuja confluência só se daria muito depois. (p. 116)

Vitrúvio $^{12}$ formulou uma teoria arquitetônica inspirada nas proporções do corpo humano.

Lembremos que Leonardo da Vinci estuda as proporções da figura humana segundo os ditames de De architectura, de Vitrúvio, que se baseia justamente nas relações do número áureo. Segundo Leonardo, as proporções humanas são perfeitas quando o umbigo divide o homem de maneira áurea. (BUSSAGLI, 1999). É necessário lembrar que Dürer realizou estudos análogos como prova a imagem... e que é espontâneo compará-la com a do homem Vitruviano de Leonardo. (BAGNI; D’AMORE, 2011, p.80)

Figura 18. As proporções do corpo humano, segundo Albrecht Dürer.

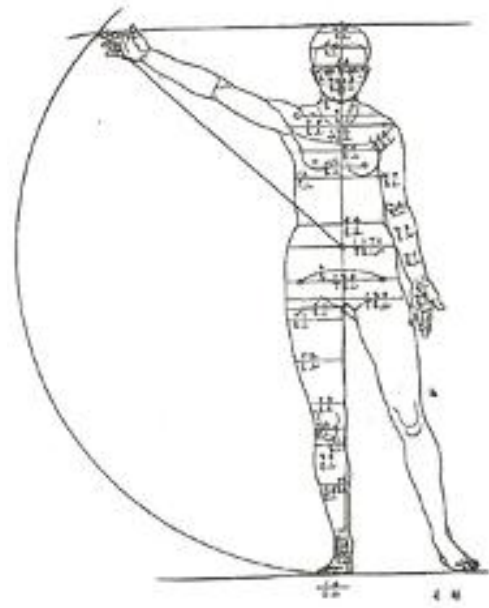

Fonte: BAGNI; D’AMORE, 2011, p. 80.

\footnotetext{
${ }^{12}$ Marcos Vitrúvio Polião, arquiteto e engenheiro romano que viveu no século I a.C. deixou como legado a sua obra em 10 volumes, aos quais deu o nome de De Architectura ( \pm 40 a.C.) que constitui o único tratado europeu do período greco-romano que chegou aos nossos dias e serviu de fonte de inspiração a diversos textos sobre construções, hidráulicas, hidrológicas e arquitetônicas desde a época do Renascimento. Os seus padrões de proporções e os seus princípios arquiteturais: utilitas, venustas e firmitas (utilidade, beleza e solidez), inauguraram a base da Arquitetura clássica.
} 
Da Vinci, não apenas sorvera tal teoria, mas reverenciou o criador desta nos brindando com o Homem Vitruviano (Cf. figura. 19).

Figura 19. O Homem Vitruviano de Leonardo Da Vinci.

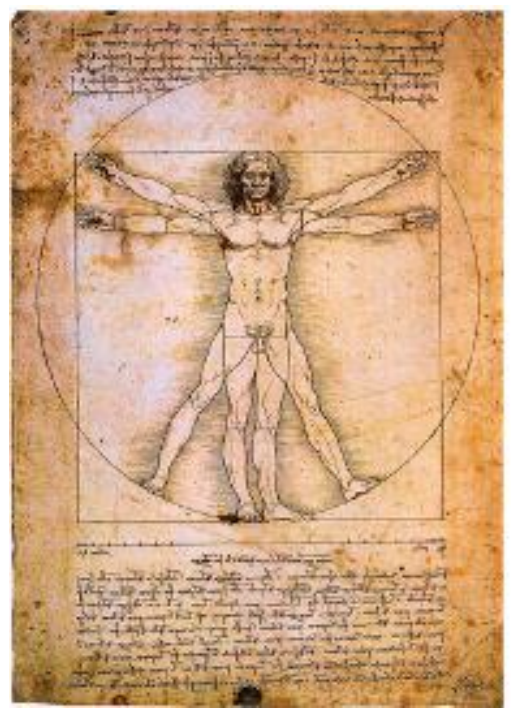

Fonte: ANTOCCIA et al, 2004, p. 81.
Figura 20. A divina proporção em $O$ homem vitruviano de Da Vinci.

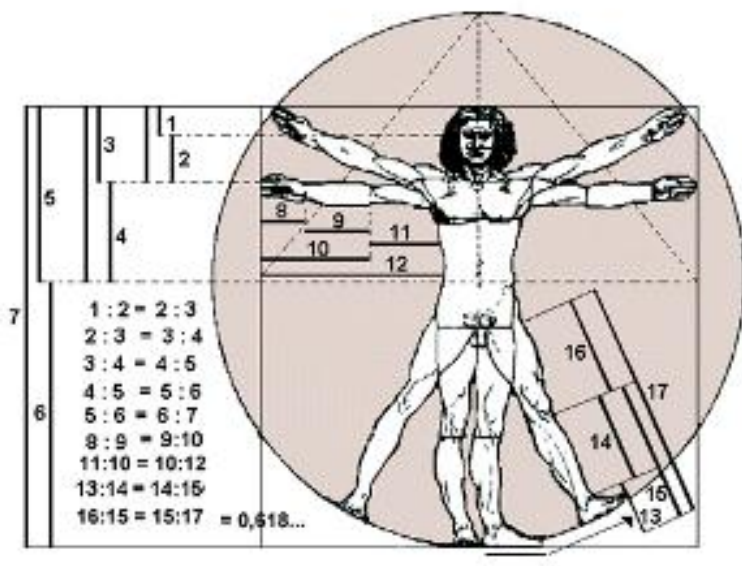

Fonte: CHAVES, 2014 - Palestra Matemática e Arte: possibilidade e pespectivas à sala de aula.

As proporções anatômicas no Homem Vitruviano estão bem representadas: (i) a altura do corpo humano e a medida do umbigo até o chão; (ii) a altura do crânio e a medida da mandíbula até o alto da cabeça; (iii) a medida da cintura até a cabeça e o tamanho do tórax; (iv) a medida do ombro à ponta do dedo e a medida do cotovelo à ponta do dedo; (v) o tamanho dos dedos e a medida da dobra central até a ponta; (vi) a medida da dobra central até a ponta dividido e da segunda dobra até a ponta; (vii) a medida do seu quadril ao chão e a medida do eu joelho até o chão. Para verificar tal representatividade e relação com a razão áurea basta verificarmos a figura a seguir.

No Homem Vitruviano a distância entre as extremidades das mãos (com os braços na perpendicular) é igual à altura do indivíduo. Quando este eleva os braços e abre as pernas, inscreve-se num círculo, cujo centro se localiza no umbigo. Aqui, mais uma vez, a razão entre a altura do indivíduo e a do umbigo é a áurea: $\phi=1,618 \ldots$ 
Tomando figuras sentadas ou eretas, com o propósito de estudar as funções assimétricas dos hemisférios cerebrais se manifestassem diferentemente em obras de artistas renomados, Christopher Tyler, neurocientista em San Francisco, propôs uma análise estatística levando em conta 4 hipóteses: (i) a do eixo principal; (ii) a da razão áurea; (iii) a do centro na cabeça; (iv) a do centro em um dos olhos. Atalay (2008, p. 189) destaca que à primeira vista, "a maioria dos observadores concordaria que, nos retratos, os olhos em geral se localizam perto do centro da tela.". Contudo, as análises de Tyler revelaram algo mais preciso: "um dos olhos, quer o composicionalmente denominante quer o outro, alinhava-se numa distribuição gaussiana (curva normal) com a reta central ou nas proximidades dela, havendo um estreito desvio-padrão de $\pm 5 \%$ da largura do quadro" (ATALAY, 2008, p. 190).

Tomando os quadros verticalmente, Tyler constatou que a altura dos olhos se achava no maior número de vezes não nas proximidades da reta horizontal central, mas nas proximidades do número de ouro depositado sobre a reta central vertical; isto é, a $\pm 61,8 \%$ da altura do quadro, como podemos constatar nas figuras 21 e 22 a seguir.

Figura 21. Mona Lisa (La Gioconda).

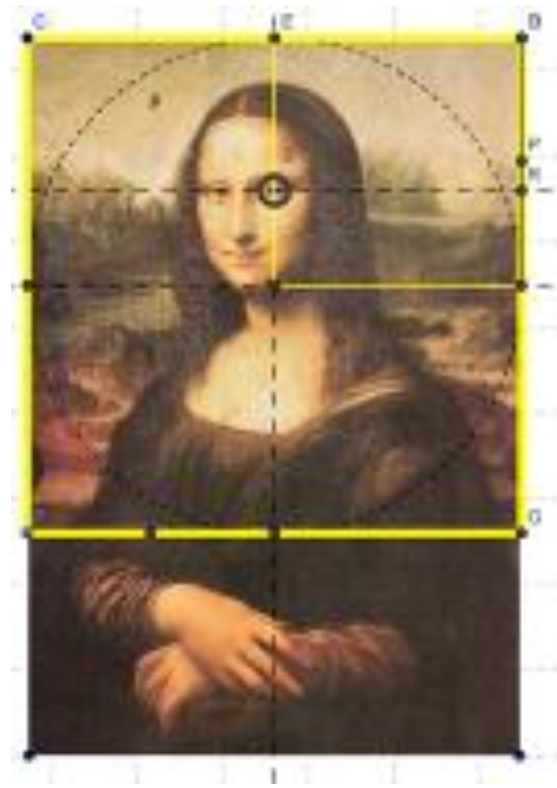

Fonte: Dados da pesquisa.
Figura 22. Dama com arminho

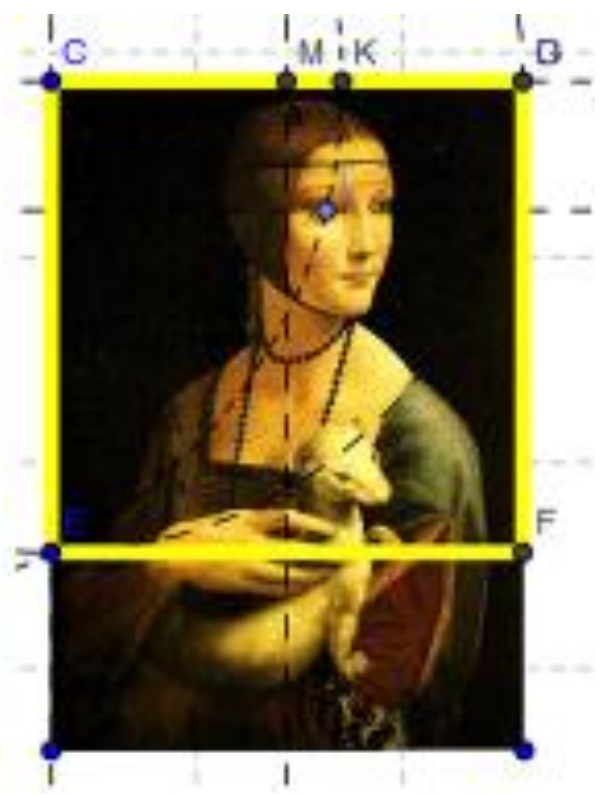

Fonte: Dados da pesquisa.

O Duque Ludovico Sforza Ludovico encarregou Da Vinci de diversas tarefas das quais lhe coube retratar Cecilia Gallerani, amante do duque. 
O retrato mostra, provavelmente, a amante do duque Ludovico, o Mouro. $\mathrm{O}$ arminho que a jovem segura docemente nos braços é disso indicativo, uma vez que esse animal fazia parte do brasão do duque. Além disso, inclui uma alusão oculta ao seu próprio nome, Gallerani, uma vez que a palavra grega para arminho é galé. Apesar do mau estado de conservação - o fundo e os cabelos foram grosseiramente pintados por cima -, o quadro é um exemplo magnífico da técnica de retrato de Leonardo (BUCHHOLZ, 1999, p. 29).

Há quase uma unanimidade nos compêndios de História da Arte no que tange a similaridade entra a índole de Cecília (determinada, articulada, ativa, vigorosa etc.) e a expressão de seu rosto retratada na obra de Da Vinci.

Leonardo da Vinci foi original não só na pose da figura feminina como também na inclusão de um animal cuja ferocidade é um contraponto à serenidade de Cecília. Pela primeira vez, o consagrado pintor usava um recurso tão distinto do ser retratado. Isso poderia conferir à personagem um defeito ou uma qualidade. Fonte: <http://pt.wikipedia.org/wiki/Dama_com_Arminho>.

Para Buchholz (1999) a Mona Lisa deveria ter o título de Retrato de uma Dama, contudo, o título de hoje deve-se a Giorgio Vasari que defendia que Leonardo retratara a mulher de um mercador, Francesco del Giocondo.

Na história da arte, o título do quadro costuma ser o do primeiro nome; no entanto, os italianos conhecem a pintura como La Gioconda. Leonardo deve ter recebido a encomenda por volta de 1503, quando Lisa tinha 24 anos (BUCHHOLZ, 1999, p. 62).

Mas há controvérsias, visto que existem outras fontes, na História da Arte que defendem que esta obra fora encomendada por Juliano de Médicis e mostra, segundo a própria Buchholz (1999), "uma 'certa dama', provavelmente uma cortesã." 
A primeira vista, a composição produz um efeito despretensioso e simples. A retratada está sentada numa cadeira de braços, à frente de uma paisagem longínqua. Por trás da figura vê-se o parapeito de uma loggia aberta. Duas colunas existentes nos lados foram eliminadas quando o quadro foi cortado. Ao contrário de outros retratos da época, não se vêem apenas o rosto e os ombros do modelo. A postura da retratada é equilibrada com precisão: olha a direito para o observador, mas o busto está voltado de lado. Assim, a figura ganha vivacidade, e a composição harmonia. As mãos sobrepostas dão unidade à composição pictória e transmitem uma impressão de dignidade descontraída. O proverbial sorriso da Mona Lisa quase não passa de uma alusão: sombras leves tocam a comissura dos lábios e os olhos. O observador tanto crê vê-la sorrir como, logo em seguida, a acha séria e distante. Através de uma desfocagem fina, quase imperceptível, o chamado sfumato ${ }^{13}$ Leonardo transmite a vaga sensação de movimento e evita a rigidez e a falta de naturalidade de muitos retratos. Em comparação com os retratos pintados com precisão por Piero dela Francesca, essa peculiaridade especial de Leonardo torna-se clara. No seu quadro nada parece palpável, fixo ou rígido. Até as formas da paisagem parecem fluir suavemente umas para dentro das outras. A figura e a paisagem foram harmonizadas entre si, tom sobre tom. Numa jóia, nenhum luxo exterior desvia a impressão de vivacidade interior que corresponde ao tema propriamente dito.

Provavelmente, Leonardo foi-se libertando, ao longo do trabalho no retrato, que se estendeu por vários anos, da razão original da sua criação, de tal modo que, de um retrato realista foi surgindo, a pouco e pouco, uma imagem ideal e uma obra de arte independente, Leonardo nunca chegou a entregar o quadro e guardou-o sempre junto de si (BUCHHOLZ, 1999, p. 62-63, 76) (ipsis verbis).

Em La Gioconda (Mona Lisa) o número áureo se faz presente nas relações entre seu tronco e cabeça, e também em elementos do rosto, como é possível verificar nas figuras 23 e 24 a seguir.

\footnotetext{
${ }^{13}$ O sfumato de Leonardo é, no fundo, um artifício para se pintar aquilo que não se vê, ou seja, o ar entre as coisas. A palavra italiana sfumato pode ser traduzida como "esfumado, turvo, nebuloso". Com isso entende-se uma característica das pinturas de Leonardo que é difícil de descrever com palavras, apesar de ser imediatamente visível ao olhar. Ainda mais difícil é descrever o modo como o pintor consegue obter esse efeito. Os teóricos da arte do Renascimento italiano utilizam a palavra sfumare para descrever a gradação imperceptível das tonalidades de cor e os valores de claro-escuro de uma pintura.
} 
Figura 23. Relação áurea presente em elementos do rosto de Mona Lisa

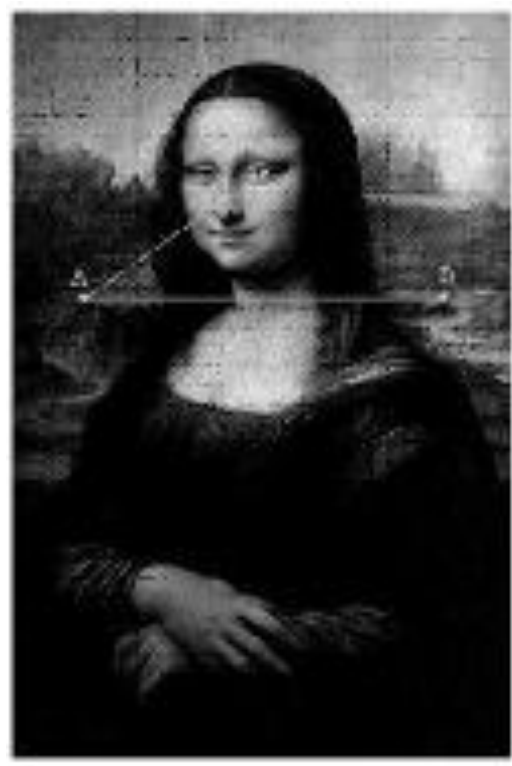

Fonte: Dados da pesquisa. Fonte: Dados da pesquisa.
Figura 24. Relação áurea presente em elementos do rosto de Mona Lisa

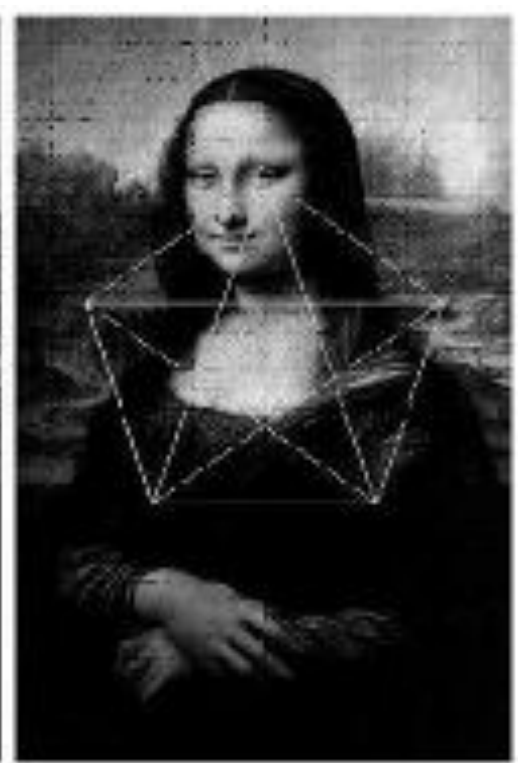

Mas existem outras leituras em relação à Mona Lisa. Na figura (25) a seguir, por exemplo, é possível verificar a utilização do retângulo áureo e, consequentemente, da espiral logarítmica para a composição e distribuição de aspectos anatômicos dessa obra. Mesmo que a gênese não esteja em Da Vinci e sua Mona Lisa, tal técnica ainda hoje é utilizada em fotografia para composição da imagem (Cf. figura 26). 
Figura 25. Retângulo áureo e

espiral logarítmica presentes

em elementos do rosto de

Mona Lisa

Figura 26. Utilização da espiral logarítmica e do retângulo áureo na composição de uma fotografia.
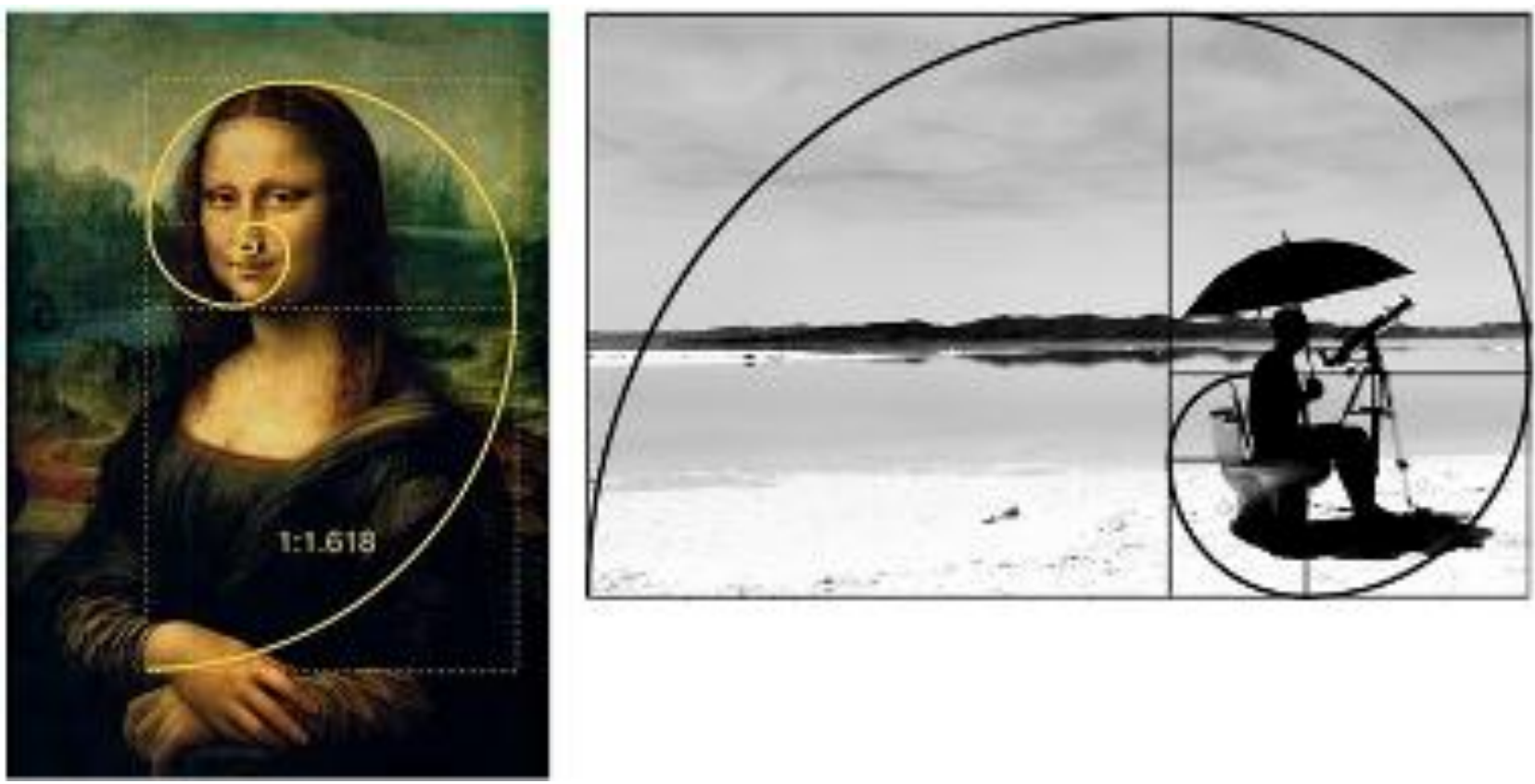

\section{CONCLUSÕES}

As leituras em relação às obras de Da Vinci que apresentamos não foram postas com o propósito de ilustrar uma possível Matemática tomando a Arte como mote. Muito menos quisemos perpetuar o regime de verdades de que tudo é Matemática, como acreditavam os pitagóricos e os platônicos. Preocupamo-nos apenas em realizar algumas leituras tomando alguns padrões numéricos e geométricos. Entendemos aqui que Matemática e Arte são formas de ler o mundo e também duas maneiras que encontramos de procurar responder perguntas que, aparentemente, não possuem respostas.

Segundo Caraça (1978),

perplexidades, dúvidas, interrogações são de todos nós e de todos os tempos. Elas são a condição necessária de todo o esforço progressivo, de toda a tentativa de passagem a um nível superior da compreensão. Que a densa névoa das perplexidades dê por vezes lugar aos traços luminosos duma certeza, aí reside o 
nosso maior motivo de orgulho como seres humanos; mas não nos esqueçamos de que a verdade de hoje é o erro de amanhã, que certeza e perplexidade se entrelaçam e reagem uma sobre a outra, ao longo desta gloriosa cadeia muitas vezes milenária que é a luta incessante do homem com a natureza e consigo próprio (CARAÇA, 1978, p. 181-182).

Bem mais do que produzir certezas, objetivamos ao longo desse texto gerar perplexidades, dúvidas e interrogações, sobretudo para que pensemos e nos inquietemos em relação a questões como: Tomar um viés entre Matemática e Arte implica em possibilidades e perspectivas à sala de aula? É possível tomar a relação biunívoca entre ambas como uma Tendência de pesquisa em Educação Matemática ou como um procedimento metodológico de ensino? Será que o viés entre Matemática e Arte configura-se como uma possibilidade de prática inovadora de ensino? Será essa relação uma trajetória e perspectiva à educação no século XXI?

O músico e arranjador lan Guest, em sua obra Arranjo: método prático" ${ }^{14}$, diz que "A deficiência em música, felizmente, não faz vítimas como na medicina ou no volante. Deitar a mão no instrumento impunemente é o começo de tudo [...] e a linha de chegada." Parafraseando Guest pensamos que uma deficiência em relação ao ensino de Matemática (que pode levar ou não a um aprendizado), felizmente, não faz vítimas como na medicina ou no volante; porém, quando tomamos o ensino de Matemática como uma forma de exclusão social (pelos níveis de retenção e evasão), quando nos limitamos a trabalhar no ambiente vigente que o caracteriza, quando passamos a defender a Matemática (com seu formalismo exacerbado), bem como certa maneira de ensinar, como algo imutável, o número de vítimas passa a ser maior do que as vítimas de trânsito ou da falta de assistência médica adequada. Por isso defendemos usar a Matemática impunemente, tal como o instrumento musical de Guest, ou como os códigos de Da Vinci; como uma ferramenta a serviço de ações educativas que sejam transformadoras e comprometidas com projetos que primam por adotar ambientes de aprendizagem que sejam investigativos sem deixarem de ser agradáveis. Observemos que a rigidez curricular que exalta o formalismo exacerbado da Matemática se contrapõe a um dos princípios norteadores para área de Matemática no Ensino Básico, apresentado nos PCN:

\footnotetext{
${ }^{14}$ GUEST, I. Arranjo: método prático. V. 1. 4. Ed. Rio de Janeiro: Lumiar, 1996, 150 p.
} 
Aprendizagem em Matemática está ligada à compreensão, isto é, à atribuição e apreensão de significado; apreender o significado de um objeto ou acontecimento pressupõe identificar suas relações com outros objetos e acontecimentos. Assim, o tratamento dos conteúdos em compartimentos estanques e numa rígida sucessão linear deve dar lugar a uma abordagem em que as conexões sejam favorecidas e destacadas. O significado da Matemática para o aluno resulta das conexões que ele estabelece entre ela e as demais áreas, entre ela e os Temas Transversais, entre ela e o cotidiano e das conexões que ele estabelece entre os diferentes temas matemáticos (BRASIL, 1998, p. 56-57).

Guest nos lembra de que aprender a falar - o maior desafio da infância - é combinar brincadeiras e desejo de se comunicar, assim como aprender a desenhar, pintar, esculpir em massinhas, quando na infância. A música, bem como as demais formas de Arte, também nasce pela mesma motivação. Referindo-se à Música Guest diz: "Não se prenda nos limites da leitura. Ela é o produto final e ameaça aposentar o ouvido, bem como a criatividade." Da mesma forma lembramos que é difícil usar a Matemática como linguagem, por isso brincar com suas ideias e princípios, sobretudo tomando referenciais da História (da humanidade, da Arte, da Matemática, das civilizações etc.) deva ser um grande desafio levado ao aluno. Ir aos procedimentos adotados pelos antigos, tentar identificar significados produzidos por civilizações que tomaram a Matemática como ferramenta, assim como Tales e Leonardo, para resolver suas práticas cotidianas, de ordem social, artística, cultural, religiosa, econômica etc., possibilita que se estabeleçam relações e se produzam - além da capacidade de argumentação, comparação e validação de processo - o desenvolvimento da Matemática como linguagem, tal como é enunciado nos princípios a seguir dos PCN:

- No ensino de Matemática, destacam-se dois aspectos básicos: um consiste em relacionar observações do mundo real com representações (esquemas, tabelas, figuras, escritas numéricas); outro consiste em relacionar estas representações com princípios e conceitos matemáticos. Nesse processo, a comunicação tem grande importância e deve ser estimulada, levando-se o aluno a 'falar' e a 'escrever' sobre a Matemática, a trabalhar com representações gráficas, desenhos, construções, a aprender como organizar e tratar dados.

- O ensino da Matemática deve garantir o desenvolvimento de capacidades como: observação, estabelecimento de relações, comunicação (diferentes linguagens), 
argumentação e validação de processos e o estímulo às formas de raciocínio como intuição, indução, dedução, analogia, estimativa (BRASIL, 1998, p. 56-57).

A motivação para aprender Matemática não se restringe a tomá-la pelo que os matemáticos consideram como cerne de sua beleza (seus pressupostos epistemológicos). Ao contrário: usar tais pressupostos como possíveis formas de leituras - favoráveis a produções de significados que não se restrinjam à Matemática pela e para a Matemática - na resolução de problemas locais, pontuais, úteis à vida e que permitam o exercício da experimentação, intuição, da investigação.

Não nos restrinjamos aos limites do formalismo, pois o formalismo matemático é produto, não processo, e ameaça a todos aqueles que pensam em usar a Matemática como uma ferramenta de leitura do mundo e de criatividade às suas vidas. Lembremo-nos que as obras de Da Vinci (produto) são frutos de observações, estudos, testagens, esboços, ensaios (processo). Basta examinar seus códigos e verificar o quanto este gênio debruçava-se na prancheta para estudar posturas, padrões anatômicos pelo viés da razão áurea.

Com essa proposta a construção do conhecimento matemático se dá pelo desejo de usar a Matemática impunemente, como um instrumento, uma obra de Arte e de forma prática. A comunicação (aprendizado) se estabelece quando o aluno experimenta a Matemática (brincando com erros e acertos) na intervenção de um problema local, na investigação de algo que Ihe é proposto quando envolve um número maior de sentidos, como o tato, associado à visão, à audição e até ao olfato, pois as obras de arte têm cheiro, sobretudo telas e livros. Isso faz sentido e gera aprendizado. Lembremo-nos que ensinar é algo distinto de aprender. O professor pode ensinar bem e isso não implica que o aluno compartilhará do mesmo espaço comunicativo que o professor. É possível que esteja aí um dos grandes problemas do ensino: acreditar que basta ensinar para aprender.

Usar a Matemática, seus princípios e procedimentos como ferramentas a serviço de temas geradores, processos investigativos, retomada à História (da humanidade, da Arte, da Matemática, das civilizações etc.), processo de leitura e interpretação de obras de arte etc. é um convite a desapegarmo-nos de uma Matemática que funciona como instrumento de exclusão social sobretudo um convite à liberdade. Trabalhar a Matemática em sala de aula dessa forma é cultivar a 
liberdade de se expressar e não deixá-la morrer. Para tal, precisamos estimular a criatividade e, diante disso, o professor de Matemática assume o compromisso de, além de tratar das estruturas matemáticas, passa a trabalhar com seus princípios para permitir que seja construído o acesso à liberdade de criar, intuir, experimentar, investigar. Os papéis das fórmulas, regras, definições, corolários, teoremas etc. deixam de serem os principais entes do processo de ensinar e são reduzidos quando comparados a propostas que possibilitem a construção do conhecimento, da criatividade.

Tal como a música e a pintura, entendemos a Matemática como uma linguagem desenvolvida e lapidada, sendo de fundamental importância que alunos e professores brinquem com ela, antes de se preocuparem com sua densa teoria e notação. Brincar para compreender seus princípios básicos. Primeiramente é preciso construir o conhecimento a respeito do que significa, em termos de ideia, adicionar, subtrair, grandezas direta ou inversamente proporcionais, ou grandezas (in)comensuráveis, para depois aprender a expressar algebricamente a leitura de um problema ou trabalhar com dado algoritmo. Dar nome a potência, raiz de equação, parábola etc. é consequência de se produzir significados pertinentes aos princípios fundamentais dessas coisas e onde elas podem ser usadas.

A atividade matemática escolar não é 'olhar para coisas prontas e definitivas', mas a construção e a participação de conhecimentos pelo aluno, que se servirá dela para compreender e transformar sua realidade (BRASIL, 1998, p. 56-57)

Uma conclusão que chegamos foi: é preciso desestabilizar os processos arcaicos de ensino, como também qualquer estrutura rígida de controle que tenta tomar o professor como agente multiplicador de ideias, valores e costumes, para que possamos transvalorizarmo-nos e com isso minimizarmos os impactos socioambientais e culturais produzidos pelo regime de verdade que privilegia o consumo, as injustiças e a destruição dos recursos naturais em prol do lucro e da imposição incisiva de suas verdades.

Defendemos como verdade que promover ambientes investigativos de aprendizagem - pautado em princípios de liberdade -, valorizando os potenciais artísticos e culturais dos alunos, constituem-se como instrumentos de desestabilização da atual ordem social vigente, mas que também é necessário desenvolver tais ambientes livremente para que não sejam capturados pelas 
instituições de sequestro, passando a sofrer restrições que inviabilizem seu caráter despojado, comprometido, sobretudo com a experimentação e com o livre pensar, com o respeito ao indivíduo e à natureza.

Optamos por desestabilizar o ensino excludente a partir de questões artísticas e históricas para que possamos subverter a concepção positivista e homilética de propagação de discursos segundo o foco da necessidade de utilizar a Matemática como base às relações de comércio, em prol de utilizá-la para minimizar impactos que prejudicam o ambiente e aflijam as pessoas. Para tal, deixamos como recomendação:

Evite aceitar as coisas sem questioná-las - teste-as antes. Nunca desista de aspirar ao aprimoramento pessoal, não importando em que fase da vida esteja: leia sempre, leia com espírito crítico, procure o significado das palavras que não conhece, para assim ampliar o vocabulário. Tenha consigo um bloquinho e faça desenhos (mesmo se já se convenceu de que não sabe desenhar); isso o tornará mais observador. Observe à maneira do cientista, usufrua à maneira do artista. Registre suas observações. Experimente, sabendo muitíssimo bem que alguns experimentos hão de fracassar. Entretanto, é assim que se alcança um conhecimento mais profundo. É importante ser curioso, é importante explorar diferentes mundos intelectuais - e é essencial buscar as correlações entre eles. 0 modelo que funcionou maravilhosamente bem para ele não fará jamais que nos tornemos outro Leonardo, um homem que tantos estudiosos consideram "o maior gênio que já existiu". Todavia, esse modelo não deixará de fazer que cada um de nós se torne muito mais criativo e seja mais ativo e efetivo no mundo intelectual que habitamos (ATALAY, 2008, p.328-329). 


\section{REFERÊNCIAS}

ANTOCCIA, Luca et al. Leonardo: arte e ciência - as máquinas. Tradução: ANTUNES, Leonardo. São Paulo, Globo, 2004.

ATALAY, Bulent. A Matemática e a Mona Lisa - a confluência da arte com a ciência. $2^{a}$ edição. São Paulo: Novo Tempo. 2009

BAGNI, G.; D`AMORE, B. Leonardo e a Matemática. São Paulo: Livraria da Física. 2011.

BARBOSA, R. M. Descobrindo padrões pitagóricos: geométricos e numéricos. São Paulo: Atual, 1993. 93p.

BICUDO, Irineu (tradução). Os Elementos. São Paulo: EdUNESP, 2009.

BONGIOVANNI, Vincenzo. O Teorema de Pitágoras: uma ligação entre uma propriedade angular e uma propriedade métrica. In: http://www.ebah.com.br/content/ABAAAAIXQAK/demonstracao-teorema-pitagoras. Acesso em 23/06/2014.

BOYER, Carl B. História da Matemática. Elza F. Gomide. São Paulo: Edgard Blücher, 1974.

BRANDÃO, Leônidas de Oliveira. IMÁTICA: a Matemática interativa na internet - secção áurea. In: http://www.matematica.br/historia/saurea.html. Visitado em 21/06/2014.

BRASIL. Secretaria de Educação Básica. Diretoria de Apoio à Gestão Educacional. Pacto nacional pela alfabetização na idade certa: quantificação, registros e agrupamentos. Ministério da Educação, Secretaria de Educação Básica, Diretoria de Apoio à Gestão Educacional. Brasília MEC/SEB: 2014, 88p.

- Ministério da Educação e do Desporto, Instituto Nacional de Estudos e Pesquisas Educacionais. Parâmetros Curriculares Nacionais para o Ensino Fundamental: terceiro e quarto ciclos do ensino fundamental. Brasília, 1998.

BUCHHOLZ, Elke Linda. Leonardo da Vinci: vida e obra. New York: Könemann Verlagsgesellschaft, 1999.

CARAÇA, Bento de Jesus. Conferências e outros Escritos. Lisboa: (?), 1978.

. Conceitos fundamentais da Matemática. Lisboa: Livraria Sá da Costa, 1989.

CHAVES, Rodolfo. Por que anarquizar o ensino de matemática intervindo em questões socioambientais? 223 p. Tese (Doutorado em Educação Matemática) - Programa de PósGraduação em Educação Matemática, Universidade Estadual Paulista Julio de Mesquita Filho, Rio Claro - São Paulo. 2004.

CEZAR, Mariana dos Santos. Produções de significados matemáticos na construção dos números reais. 151 p. Dissertação (Mestrado em Ensino de Ciências e Matemática) - EDUCIMAT, Instituto Federal do Espírito Santo - IFES, Vitória. 2014.

EVES, Howard. Introdução à história da matemática. Campinas (SP): Ed. Unicamp. 2004.

GUERATO, Elisabete. A Matemática na Grécia: Tales, Pitágoras, Euclides, Arquimedes, 
Eratóstenes, Apolônio, Hiparco, Ptolomeu, Herão, Diofanto, Papus e Menelau. In:

http://www.cefetsp.br/edu/guerato/mathist/apresentacoes/a matematica na grecia.pdf.

Visitado em 16/06/2014.

HUISMAN, Denis. Dicionário dos filósofos. São Paulo: Martins Fontes, 2001.

LÍVIO, Mario. Razão Áurea - a história de Fi, um número surpreendente. 3ạ edição. Rio de Janeiro: Record. 2008.

LOPEZ, Alvarez. O enigma das pirâmides. São Paulo: Hemus, 1978.

MOREIRA, N., C.; CABRAL, M. Curso de Análise Real. 2. ed. V. 2.4. Rio de Janeiro: Departamento de Matemática Aplicada, Instituto de Matemática, UFRJ, 2011.

PINTO, Nilda Helena S, Corrêa. Desenho geométrico. v.4 - teoria. 1 ed. São Paulo: Moderna, 1991.

SILVA, Ana; PENA, Nuno. Números, o levantar do veú. http://www.mat.uc.pt/ mat1042/docs/am/

RelatorioAM1Final.pdf, visitado em 13.06.2014.

SKOVSMOSE, Ole. Cenários para investigação. BOLEMA (PGEM/UNESP), n.14, p. 66-91. 2000.

WEIL, P.; D'AMBROSIO, U.; CREMA, R. Rumo à nova transdisciplinaridade: sistemas abertos de conhecimentos. 2. ed. São Paulo: Summus, 1993.

WHITE, Michael. Leonardo - o primeiro cientista. 2a edição. Rio de Janeiro: Record. 2002.

ZAHN, Maurício. Sequência de Fibonacci e o Número de Ouro. Unimpa, Bagé, Rio Grande do Sul: Ciência Moderna. 2011.

ZALESKI FILHO, Dirceu. Matemática e Arte. São Paulo: Autêntica Editora. 2013. (Tendências em Educação Matemática). 